OPEN ACCESS

Edited by:

Gustavo Javier Martinez, Rosalind Franklin University of Medicine and Science, United States

Reviewed by:

Xindong Liu,

Army Medical University, China Imke Atreya, University Hospital Erlangen, Germany Kenji Chiba,

Mitsubishi Tanabe Pharma

Corporation, Japan

*Correspondence:

Donghai Wang donghai.wang@duke.edu

tThese authors have contributed equally to this work

Specialty section: This article was submitted to T Cell Biology,

a section of the journal

Frontiers in Immunology

Received: 14 December 2020 Accepted: 24 February 2021

Published: 22 March 2021

Citation:

Swan G, Geng J, Park E, Ding Q, Zhou J, Walcott C, Zhang JJ, Huang H-I, Hammer GE and Wang D (2021) A Requirement of Protein Geranylgeranylation for Chemokine Receptor Signaling and Th17 Cell Function in an Animal Model of Multiple Sclerosis.

Front. Immunol. 12:641188 doi: 10.3389/fimmu.2021.641188

\section{A Requirement of Protein Geranylgeranylation for Chemokine Receptor Signaling and Th17 Cell Function in an Animal Model of Multiple Sclerosis}

\author{
Gregory Swan ${ }^{1,2 \dagger}$, Jia Geng ${ }^{1 \dagger}$, Eunchong Park ${ }^{2}$, Quanquan Ding ${ }^{1}$, John Zhou ${ }^{1}$, \\ Ciana Walcott ${ }^{1}$, Junyi J. Zhang ${ }^{2}$, Hsin-I Huang ${ }^{2}$, Gianna Elena Hammer ${ }^{2}$ and \\ Donghai Wang ${ }^{1,2 *}$
}

${ }^{1}$ Division of Rheumatology and Immunology, Department of Medicine, Duke University School of Medicine, Durham, NC, United States, ${ }^{2}$ Department of Immunology, Duke University School of Medicine, Durham, NC, United States

Precisely controlled lymphocyte migration is critically required for immune surveillance and successful immune responses. Lymphocyte migration is strictly regulated by chemokines and chemokine receptors. Here we show that protein geranylgeranylation, a form of post-translational protein lipid modification, is required for chemokine receptor-proximal signaling. Mature thymocytes deficient for protein geranylgeranylation are impaired for thymus egress. Circulating mature $T$ cells lacking protein geranylgeranylation fail to home to secondary lymphoid organs or to transmigrate in response to chemokines in vitro. Mechanistically, protein geranylgeranylation modifies the $\gamma$-subunits of the heterotrimeric small GTPases that are essential for chemokine receptor signaling. In addition, protein geranylgeranylation also promotes the differentiation of IL-17-producing $T$ helper cells while inhibiting the differentiation of Foxp3 ${ }^{+}$regulatory $T$ cells. Finally, mice with $T$ cell lineage-specific deficiency of protein geranylgeranylation are resistant to experimental autoimmune encephalomyelitis induction. This study elucidated a critical role of protein geranylgeranylation in regulating T lymphocyte migration and function.

Keywords: adaptive immune response, $\mathrm{T}$ cells, autoimmunity, lymphocyte migration, protein geranylgeranylation

\section{INTRODUCTION}

T cell-mediated adaptive immune response depends on precisely controlled lymphocyte trafficking $(1,2)$. Under homeostatic conditions, naive T cells enter secondary lymphoid organs (SLOs) to scan for antigenic peptide on antigen presenting cells (2). In the presence of cognate antigen, antigen-specific $\mathrm{T}$ cells undergo activation, proliferation and differentiation into effector $\mathrm{T}$ cells that subsequently leave SLOs and travel through the circulation to peripheral target sites to orchestrate immune responses culminating in the elimination of pathogens or neoplastic cells (3). Likewise, such trafficking processes has also been targeted to treat autoimmune diseases.

The exquisite process of lymphocyte trafficking is critically regulated by three types of receptorsselectins, chemokine receptors and integrins (4). Selectin interaction with their ligands results 
in the tethering and rolling of lymphocytes along vascular wall that in turn enables the contact between chemokine ligands on endothelial cells and chemokine receptors on lymphocytes (5). The chemokine and its receptor interaction initiates a socalled "inside-out" signaling cascade within lymphocytes that converts integrins from curved, inactive conformation into an extended, active one (6). Activated integrins such as lymphocyte activation antigen-1 (LFA-1) then bind to integrin ligands such as intercellular adhesion molecule-1 (ICAM-1) on the vascular endothelial cells leading to the arrest and subsequent transmigration of lymphocytes into the paracortical region of lymph nodes $(1,5)$.

Chemokine receptors are G-protein coupled receptors (GPCRs) that depend on heterotrimeric small GTPases to relay signals from the plasma membrane to downstream proximal signaling components such as phosphoinositol-3-kinases to initiate signaling cascades that control lymphocyte trafficking (7). Despite the dramatic expansion of our knowledge in the past few decades, how the complex signaling network downstream of chemokine receptors fine-tunes the outcome of an immune response remains incompletely understood.

Protein geranylgeranylation is a form of post-translational lipid modification of proteins with geranylgeranyl pyrophosphate (GGPP) as a substrate and regulates a plethora of essential physiological processes (8). Protein geranylgeranylation is catalyzed by the heterodimeric protein geranylgeranyl transferase-I (GGTase-I) consisting of an $\alpha$ and a $\beta$ subunit. Using a conditional allele of the gene encoding the $\beta$-subunit of GGTase-I (Pggt1b) (9), we have previously elucidated molecular mechanisms by which protein geranylgeranylation regulates innate immune signaling downstream of toll-like receptors (10) and RIG-I-like receptors (11) in myeloid cells. López-Posadas et al. (12) reported that loss of Pggtlb in $\mathrm{T}$ cells in Pggt $1 b^{f l / f l} C D 4 C r e$ mice led to impaired RhoA function, increased integrin $\alpha 4 \beta 7$ expression and preferential localization of inflammatory $\mathrm{CD}^{+} \mathrm{T}$ cells to colon and colitis. Du et al. elucidated that Pggt1b is required for thymus egress by bridging chemokine-induced activation of Cdc42 and Pak signaling (13). Both studies relied on the Pggt $1 b^{f l / f l} C D 4 C r e$ mouse strain in which there is a severe $\mathrm{T}$ lymphopenia in the periphery. In addition, the majority of mature $\mathrm{T}$ cells in the periphery in those mice displayed an activated phenotype. These abnormalities in $\mathrm{T}$ cells makes it difficult to study peripheral $\mathrm{T}$ cell function using Pggt $1 b^{f l / f l}$ CD4Cre mice.

To study how protein geranylgeranylation regulates $\mathrm{T}$ cellmediated adaptive immune response, we have generated a mouse strain in which the expression of Pggt $1 b$ was abrogated in mature T lymphocytes by means of a distal Lck promoter-driven Cre and the Pggt1b conditional allele. Using this mouse strain, we demonstrate that protein geranylgeranylation deficiency in $\mathrm{T}$ cells lead to defective adaptive immune response due to impaired T lymphocyte migration. Mechanistically, we show that this impairment is, at least in part, due to the loss of geranylgeranylation of the $\gamma$-subunits of the chemokine receptor-associated heterotrimeric small GTPases. As a result, Pggt1b-deficient naive $\mathrm{T}$ cells are defective in targeted trafficking to SLOs while Pggt1b-deficient effector $\mathrm{T}$ cells are not able to emigrate from SLOs into the circulation after primary immunization. Consequently, mice with $\mathrm{T}$ cell-specific deletion of Pggtlb are resistant to the induction of experimental autoimmune encephalomyelitis (EAE). We further demonstrate that in the absence of protein geranylgeranylation naive $\mathrm{CD} 4^{+} \mathrm{T}$ cells preferentially differentiate into induced Foxp $3^{+}$regulatory T cells (iTregs) over IL-17-producing T helper (Th17) cells. These findings revealed a pivotal role of protein geranylgeranylation in regulating $\mathrm{T}$ cell-mediated adaptive immune response.

\section{MATERIALS AND METHODS}

\section{Mice}

Pggt $1 b^{f l / f l}$ mice generated as previously described (9) were crossed with $d L c k C r e$-transgenic mice (14) to generate the Pggt $1 b^{f l / f l} d$ LckCre mouse strain. Pggt $1 b^{f l / f l} d L c k C r e$ mice and littermate control Pggt1 $b^{f l / f l}$ or Pggt1 ${ }^{f l /}+d L c k C r e$ mice were used in the experiments as indicated in each figure. 2D2-TCRtransgenic strain of mice (15) was purchased from Jackson Laboratories and was crossed with Pggt $1 b^{f l / f l} d L c k C r e$ mice to generate the 2D2- Pggt $1 b^{f l / f l} d L c k C r e$ compound transgenic mice. Mouse strains were maintained in specific pathogenfree conditions in the animal facility at Duke University, and the animal protocols were performed in accordance with the guidelines set forth by the Institutional Animal Care and Use Committees of Duke University.

\section{Flow Cytometry Analysis}

Lymphocytes from spleen, thymus, lymph nodes, and blood were stained with antibodies in FACS buffer that contains PBS, 2\%BSA and $1 \mathrm{mM}$ EDTA. Leukocytes were isolated from spinal cord of mice immunized to induce EAE according to a protocol described by Manglani et al. (16). The antibodies used in our analysis is listed here: CD4 (clone GK1.5), CD8 $\alpha$ (clone 53-6.7), CD25 (clone PC61), CD62L (clone MEL14), TCR $\beta$ (clone H57-597), CD45(clone 30-F11), CD44 (clone IM7), CD11c (clone N418), CD11b (clone M1/70), CD64 (clone X54-5/7.1), I-A/I-E (clone M5/114.15.2), Ly6C (clone HK1.4), mIL-17A (clone TC11-18H10.1), mGM-CSF (clone MP1-22E9), IFN $\gamma$ (clone XMG1.2), mIL-10 (clone JES5-16E3), mFoxp3 (FJK-16s), CCR6 (clone 29-2L17), CCR7 (clone $4 \mathrm{~B} 12$ ), Integrin $\alpha 4 \beta 7$ (clone DATK32). Those antibodies are from Biolegend. Intracellular cytokine staining and Foxp3 staining were performed per manufacturer's instructions (Invitrogen GAS003 for cytokines and eBioscience 00-552300 for Foxp3). Flow cytometry data were acquired on BD FACSCanto II or BD LSRFortessa (BD Biosciences) and analyzed using Flowjo (BD). For leukocytes isolated from EAE mice described in Figure 5 and Supplementary Figure 3, we used an antibody panel and gating strategy described by Caravagna et al. (17).

\section{In vitro T Cell Cultures}

Pooled cells from spleen and lymph nodes were first enriched for $\mathrm{CD}^{+}{ }^{+} \mathrm{T}$ cells with Magnisort mouse CD4 T cell enrichment kit (eBioscience 8804-6821-74) and then stained and sorted for $\mathrm{CD}^{+} \mathrm{CD}^{-} 5^{-} \mathrm{CD} 44^{\text {low }} \mathrm{CD} 62 \mathrm{~L}^{\text {high }}$ naive $\mathrm{T}$ cells. Sorted 
naive $\mathrm{CD} 4^{+} \mathrm{T}$ cells were used for in vitro cultures in IMDM (Life Science 12440-053) supplemented with $\beta$-mercaptoethanol, $10 \%$ fetal bovine serum and $1 \%$ penicillin-streptomycin. For survival experiment, naive $\mathrm{T}$ cells were cultured in the presence or absence of mIL-7 $(20 \mathrm{ng} / \mathrm{ml})$. For $\mathrm{T}$ cell activation, naive $\mathrm{T}$ cells were plated on cell culture plates pre-coated with goat anti-hamster IgG (MP Biomedicals, 0856984) and in the presence of hamster anti-mouse CD3 $\varepsilon$ (eBioscience 160031-86) and hamster anti-mouse CD28 (eBioscience 1600281-86) antibodies and differentiated into different subsets using reagents and recipes listed in the table below: mIL2 (Biolegend 575404), mIL-12 (Biolegend, 577004), mIL4 (Biolegend 574304), mTGF $\beta 1$ (Biolegend 736102), mIL6 (Biolegend 575702), $\alpha \mathrm{IFN} \gamma$ (Biolegend 505812), $\alpha \mathrm{mIL}-$ 4 (Biolegend 504108), amIL-6 (Biolegend 501110), mIL-1 (Peprotech 211-11B), mIL-23 (R\&D systems 1887 CF), mIL-7 (Biolegend 577806). For the culture of pathogenic Th17 cells see EAE induction by adoptively transfer of Th17 cells.

Final Concentrations of Differentiation Antibodies and Cytokines.

\begin{tabular}{|c|c|c|c|c|c|}
\hline & Th0 & Th1 & Th2 & Th17 & Treg \\
\hline$\alpha-\mathrm{CD} 3 \varepsilon$ & $1.0 \mu \mathrm{g} / \mathrm{ml}$ & $1.0 \mu \mathrm{g} / \mathrm{ml}$ & $1.0 \mu \mathrm{g} / \mathrm{ml}$ & $1.0 \mu \mathrm{g} / \mathrm{ml}$ & $1.0 \mu \mathrm{g} / \mathrm{ml}$ \\
\hline$\alpha-C D 28$ & $1.0 \mu \mathrm{g} / \mathrm{ml}$ & $1.0 \mu \mathrm{g} / \mathrm{ml}$ & $1.0 \mu \mathrm{g} / \mathrm{ml}$ & $1.0 \mu \mathrm{g} / \mathrm{ml}$ & $1.0 \mu \mathrm{g} / \mathrm{ml}$ \\
\hline mlL-1 & & & & $\begin{array}{l}20 \mathrm{ng} / \mathrm{ml} \\
\text { (Pathogenic) }\end{array}$ & \\
\hline mlL-2 & & $20 \mathrm{ng} / \mathrm{ml}$ & $20 \mathrm{ng} / \mathrm{ml}$ & & 20 ng/ml \\
\hline mlL-4 & & & $50 \mathrm{ng} / \mathrm{ml}$ & & \\
\hline mlL-12 & & $20 \mathrm{ng} / \mathrm{ml}$ & & & \\
\hline mlL-6 & & & & $50 \mathrm{ng} / \mathrm{ml}$ & \\
\hline mlL-23 & & & & $\begin{array}{l}20 \mathrm{ng} / \mathrm{ml} \\
\text { (Pathogenic) }\end{array}$ & \\
\hline mTGF $\beta 1$ & & & & $0.3 \mathrm{ng} / \mathrm{ml}$ & $5.0 \mathrm{ng} / \mathrm{ml}$ \\
\hline$\alpha-m \mid L-4$ & & $0.5 \mu \mathrm{g} / \mathrm{ml}$ & & $0.5 \mu \mathrm{g} / \mathrm{ml}$ & $0.5 \mu \mathrm{g} / \mathrm{ml}$ \\
\hline$\alpha-\mathrm{mlFN} \gamma$ & & & $0.5 \mu \mathrm{g} / \mathrm{ml}$ & $0.5 \mu \mathrm{g} / \mathrm{ml}$ & $0.125 \mu \mathrm{g} / \mathrm{ml}$ \\
\hline$\alpha-m \mid L-6$ & & & & & $0.5 \mathrm{ng} / \mathrm{ml}$ \\
\hline
\end{tabular}

\section{Transfection of 293 Cells for the Production of Retrovirus and Infection of Th17 Cells}

For preparation of retrovirus, retroviral vector DNA along with an EcoPac packaging vector were transfected into 293 cells using calcium phosphate method (18). Culture media were changed into fresh ones $24 \mathrm{~h}$ later. Culture supernatants were harvested, filtered through a $0.45 \mu \mathrm{m}$ filter and centrifuged at $6,000 \mathrm{~g}$ overnight. The opaque virus pellet was resuspended with fresh medium and used for transduction of Th17 cells by replacing the supernatant of day 3 culture of Th17 cells with the virus preparation and spinoculate at 2,000 rpm for $1 \mathrm{~h}$. The Th17 cell culture plate was then incubated at $37^{\circ} \mathrm{C}$ for $5 \mathrm{~h}$, and the medium was replaced with Th17 culture cocktail and cultured for additional $18 \mathrm{~h}$ before proceeding to further experiments.

\section{Real Time PCR}

Real time PCR was performed as described previously (11) using primers listed here:

\begin{tabular}{|c|c|c|}
\hline mPggt1b & CCTTCTGTGGCATTGCGTCA & CAACAAGGCGATCTTGAGTTG \\
\hline mGapdh & TGGCAAAGTGGAGATTGTTGCC & AAGATGGTGATGGGCTTCCCC \\
\hline mGngt1 & $\begin{array}{l}\text { CTGGAGAGAATGATGGTTTCCAA } \\
\text { ATC }\end{array}$ & ACACAGCCTCCTITGAGTTCC \\
\hline mGngt2 & CCCACGTGATCTGATTTCCAAG & $\begin{array}{l}\text { CACACAAGTGCCTTTCTCCT } \\
\text { TG }\end{array}$ \\
\hline mGng2 & ACCGCCAGCATAGCACAAG & AGTAGGCCATCAAGTCAGCAG \\
\hline mGng3 & GCACTATGAGTATTGGTCAAGCA & $\begin{array}{l}\text { GTGGGCATCACAGTATGTC } \\
\text { ATC }\end{array}$ \\
\hline mGng4 & GGCATGTCTAATAACAGCACCA & CACTGGGATGATGAGGGGG \\
\hline mGng5 & ATGTCGGGTTCTTCTAGCGTC & GGTCTGAAGGGATTCGTACTT \\
\hline mGng7 & TCAGGTACTAACAACGTCGCC & CAGTAGCCCATCAGGTCTGAC \\
\hline mGng8 & TCGCATGAAGGTGTCGCAG & CTTGTCGCGGAAGGGATTCTC \\
\hline mGng10 & GCCAGCGTGAGCGCCC & GCAGCAGGGCGTCCTTGC \\
\hline mGng11 & $\begin{array}{l}\text { GTCAAGTTGCAGAGACAACAGGT } \\
\text { ATCTAAATG }\end{array}$ & $\begin{array}{l}\text { GATTCCCTTAACCAGAGGATC } \\
\text { CTC }\end{array}$ \\
\hline mGng12 & ATGTCCAGCAAGACGGCAAG & GAGGTCGGTATGCCCATCAG \\
\hline nGng13 & GTCCAAGGAGATCGACAAATGC & CCAGCACCCTCATACCTITGA \\
\hline
\end{tabular}

\section{EAE Induction}

Murine myelin oligodendrocyte glycoprotein (MOG) 35-55 peptide with a sequence as MEVGWYRSPFSRVVHLYRNGK synthesized by United Biosystems was dissolved in sterile water at $2 \mathrm{mg} / \mathrm{ml}$. Equal volume of MOG and complete Freud's adjuvant (CFA) containing $4 \mathrm{mg} / \mathrm{ml}$ of heat-killed M. tuberculosis H37 RA (Fisher Scientific DF3114-33-8) were mixed and emulsified. Two hundred microliter of the emulsified mixture were injected subcutaneously in the flanks of mice on day 0. Pertussis toxin (200 ng/mouse) was injected intraperitoneally on day 0 and day 2. Disease was scored during daytime with the criteria: 0.5 , partial tail limpness; 1 , tail limpness; 1.5 , reversible impaired righting reflex; 2, impaired righting reflex; 2.5 , paralysis of one hind limb; 3 , paralysis of both hind limbs; 3.5 , paralysis of both hind limbs and one fore limb; 4, paralysis of both fore limbs and hind limbs; 5 , death or body weight below $80 \%$ of day 0 .

\section{EAE Induction by Adoptively Transfer of Th17 Cells}

Purified naive $\mathrm{CD}^{+} \mathrm{T}$ cells $\left(\mathrm{CD} 4^{+} \mathrm{CD} 25^{-} \mathrm{CD} 62 \mathrm{~L}^{\text {high }} \mathrm{CD} 44^{\text {low }}\right)$ from 2D2 TCR transgenic mice (15) on Pggt1b fl/fl or $P g g t 1 b^{f l / f l} L c k C r e$ background were activated as described in In vitro $T$ cell cultures in the presence of mIL-6 $(20 \mathrm{ng} / \mathrm{ml})$, mTGF $\beta 1(0.3 \mathrm{ng} / \mathrm{ml})$, anti-mIL-4 and anti-mIFN $\gamma(0.5 \mu \mathrm{g} / \mathrm{ml}$ each) for $48 \mathrm{~h}$ and then changed into medium containing mIL-6, $\mathrm{mIL}-23, \mathrm{mIL}-1 \beta(20 \mathrm{ng} / \mathrm{ml}$, each) and anti-mIL-4 and anti$\operatorname{mIFN} \gamma(0.5 \mu \mathrm{g} / \mathrm{ml}$, each $)$ and cultured for an additional $72 \mathrm{~h} .3$ $\times 10^{6}$ cells/mouse were injected $i . v$. into C57BL/6 recipient mice on day 0 . Disease score and body weight of recipient mice were monitored daily for 20 consecutive days. 


\section{In vitro Chemotaxis}

$100 \mu \mathrm{l}$ of serum free medium containing 350,000 cells (splenocytes for CCL21 chemotaxis or Th17 cells for CCL20 chemotaxis) were loaded into the upper chamber of a transwell insert (3421, Corning) as input. The lower chambers were preloaded with $600 \mu \mathrm{l}$ of medium with or without CCL21 or CCL20 and the plate was incubated at $37^{\circ} \mathrm{C}, 5 \% \mathrm{CO}_{2}$ for $6 \mathrm{~h}$. CCL20 induced Gng13-reconstituted Th17 cell migration, vector or Gng13 transduced Pggt1b-deficient Th17 cells were performed as described above, migration efficiency was calculated on GFP-positive (transduced) cells. For CCL21 chemotaxis, input and cells that migrated into the lower chamber were stained for TCR $\beta, C D 4$ and $C D 8 \alpha$ and analyzed with flow cytometry to calculate the cell numbers of each subsets. Migration efficiency is calculated according to this formula: \%Input $=$ Number of cells migrated into the lower chamber/Number of cells of input.

\section{In vivo Homing of Purified CD4 ${ }^{ \pm}$Naive T Cells}

$\mathrm{CD}^{+}$naive $\mathrm{T}$ cells were enriched using the Magnisort Naive $\mathrm{T}$ cell Enrichment kit (Thermo Fisher) and labeled with CellTrace Far Red kit (ThermoFisher, C34572) or Cell Proliferation Dye eFluor450 (Thermo Fisher, 65-0842-85). Cells from $P g g t 1 b^{f l / f l} d L c k$-Cre or Pggt $1 b^{f l / f l}$ littermate control mice were mixed at a 1:1 ratio and i.v. injected into wild-type recipient mice. Four hours later, spleen, blood, and peripheral lymph nodes were harvested and the frequency of $\mathrm{CD}^{+}$ naive $\mathrm{T}$ cells homing into SLOs were calculated by dividing cell numbers recovered in each organ by the total cell numbers inoculated.

\section{Immunoblot}

Cells were lysed with RIPA lysis buffer $(25 \mathrm{mM}$ Tris- $\mathrm{HCl}(\mathrm{pH}$ 7.4), $150 \mathrm{mM} \mathrm{NaCl}, 5 \mathrm{mM}$ EDTA, $0.1 \%$ SDS, $0.5 \%$ sodium deoxycholate, $1 \%$ triton $\mathrm{X}-100$ ) supplemented with protease and phosphatase inhibitors. Protein concentrations were determined to ensure that each well was loaded with $5 \mu \mathrm{g}$ of total proteins. Protein samples were resolved on SDS-PAGE gels and subjected by immunoblot with the following antibodies: Pggtlb (Sigma HPA030646), npRapla (Santa Cruz sc1482), Phospho-Akt S473 (Cell Signaling, 4060), phosphor-Gsk3 $\beta$ Ser9 (Cell Signaling 9322), phosphor-Erk (Cell Signaling, 9101), phosphor-Stat3 Tyr705 (Cell Signaling, 9145), phosphor-Smad2 (Cell Signaling 3108), phosphor-Smad3 (Cell Signaling, 9520), and $\beta$-Actin-HRP (Sigma, A3854).

\section{RESULTS}

\section{Establishment of the Pggt1 $b^{f / f l}$ dLckCre Strain of Mice}

To study the function of protein geranylgeranylation in mature $\mathrm{T}$ lymphocytes, we have generated a mouse strain that abrogates the expression of Pggt1b specifically in $\mathrm{T}$ lymphocytes by crossing mice carrying the conditional Pggt1b allele $\left(\right.$ Pggt $\left.^{f l /}\right)$ (9) with a dLckCre (14) transgenic strain of mice. When combined with a loxP sites-flanked

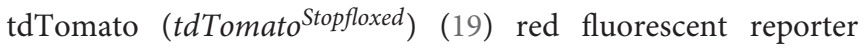
and consistent with previous findings, the $d L c k C r e$ transgene expression was first seen in post-positive selection double positive (DP) thymocytes that extended to CD4 and CD8 single positive (SP) cells in the thymus. However, the $d L c k C r e$ transgene expression was not with $100 \%$ penetration in the thymus with a higher deletion efficiency in CD8 SP than in CD4 SP thymocytes (Supplementary Figures 1A-C). Consistently, quantitative RT-PCR analysis showed that Pggt1b expression was not significantly affected in DP thymocytes and was diminished but not abrogated in CD4 and CD8 SP thymocytes, indicating that Cre-mediated deletion of Pggt1b was incomplete in bulk CD4 and CD8 SP thymocytes in the thymus (Supplementary Figure 1D). This is further supported by immunoblot showing that Pggt1b expression was largely unaltered in total thymocytes from Pggt $1 b^{f / f l} d L c k C r e$ mice (Supplementary Figure 1E). Nevertheless, non-geranylgeranylated Rapla protein were weakly detected in thymocytes from Pggt $1 b^{f l / f l} d L c k C r e$ mice, indicating that a fraction of such thymocytes had lost Pggtlb. This is consistent with the transcript abundance and the fluorescence reporter results. However, naive $\mathrm{CD}^{+}{ }^{+} \mathrm{T}$ cells isolated from spleen and lymph nodes displayed a near complete deletion of Pggt1b both at the transcript and protein level (Supplementary Figures 1F,G). Therefore, we have established a mouse model with abolition of Pggt1b expression in peripheral mature naive $\mathrm{T}$ cells.

\section{Defective Thymocytes Egress in Pggt1 $b^{f / / f l}$ dLckCre Mice}

Mature thymocytes that are ready to exit into the periphery are predominantly CD4 or CD8 SP, with down-regulated the activation marker CD69, and up-regulated CD62L and sphingosine-1-phosphate receptor 1 (S1PR1), the primary chemokine receptor essential for thymic egress (3, 20). The thymi of Pggt $1 b^{f l / f l} d L c k C r e$ mice exhibited an increased number of CD4 and CD8 SP thymocytes compared to that in $P g g t 1 b^{f l / f l}$ littermate controls (Figures 1A,C) despite the total number of thymocytes being largely unaffected (Figure 1B). Extra subpopulations of CD69 $9^{\text {low }}$ CD62L $\mathrm{L}^{\text {high }}$ amongst both CD4 and CD8 SP thymocytes emerged in the thymi of the Pggt $1 b^{f l / f l} d L c k C r e$ mice (Figures 1A,D,E) that were not present in that of the wild-type littermate controls. This phenotype resembles that in S1pr1-deficient mice $(3,20)$, suggesting that protein geranylgeranylation regulates S1PR1 expression or signaling. An analysis of the S1PR1 expression on thymocytes, particularly the CD69 low CD62L high subpopulation from the thymi of the Pggt $1 b^{f / f l}$ $d L c k C r e$ mice, showed that cell surface S1PR1 (Figure 1A) and integrin $\alpha 4 \beta 7$ (data not shown) expression was normal, 
A
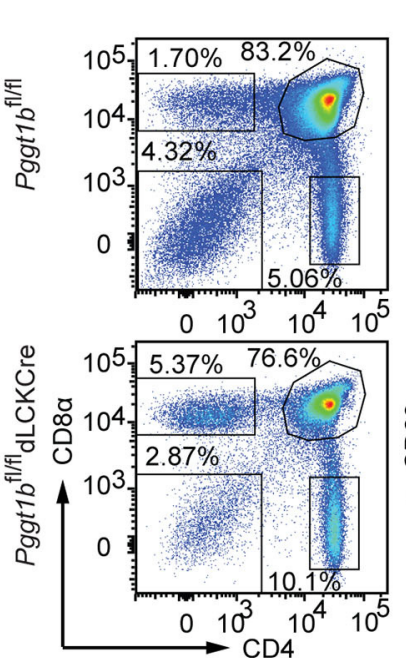

B

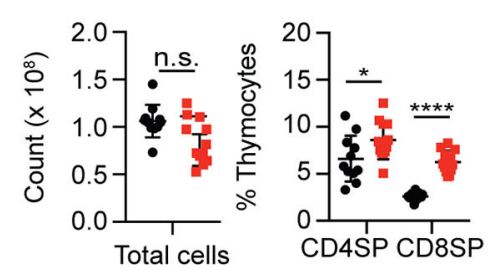

CD4SP
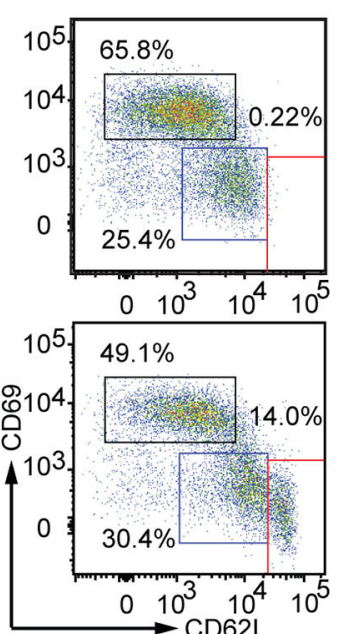
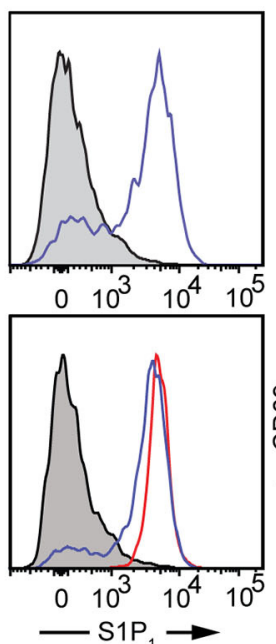

D

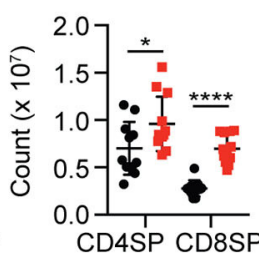

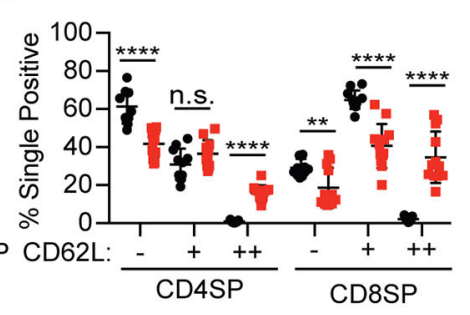

CD8SP
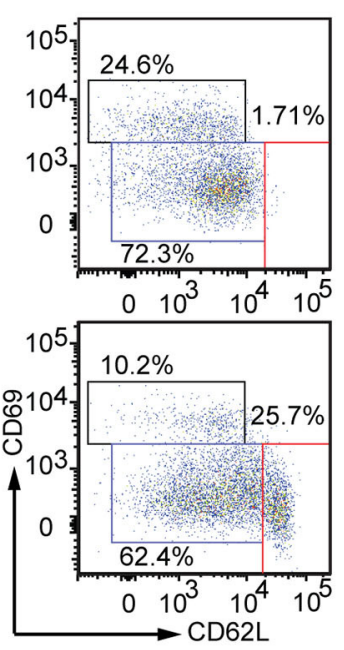

E
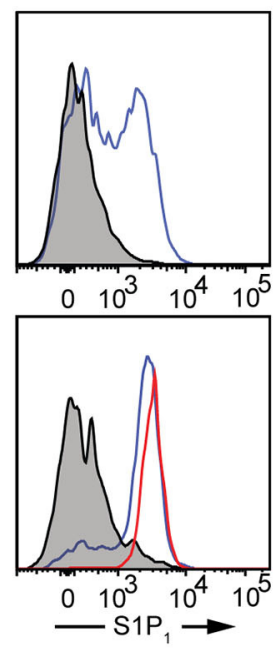

- Pggt1 bifl 8.07 Pggt1 $b^{\mathrm{fifl}}$

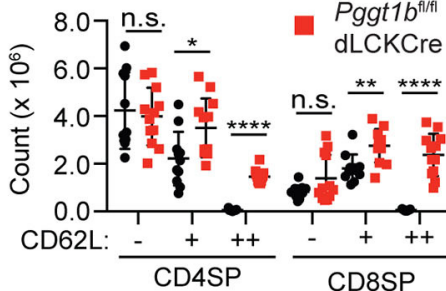

FIGURE 1 | Defective mature thymocytes egress in Pggt1 $b^{f / / f l}$ dLckCre mice (A) Flow cytometry analysis of thymic CD4 SP and CD8 SP cell expression of CD69 and

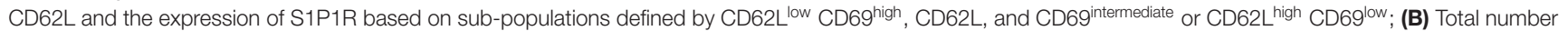
of thymocytes; (C) the percentage and number of CD4 SP and CD8 SP of total thymocytes; (D) percentage and the total number of CD4 SP and CD8 SP subpopulations described in (A). Each dot in the graphs (B-E) represents a single mouse (n.s. statistically not significant; ${ }^{\star} p<0.05,{ }^{{ }^{* *}} p<0.01,{ }^{* \star *} p<0.001,{ }^{* \star \star *} p<$ 0.0001 , unpaired $t$-test).

suggesting that Pggtlb deficiency likely results in defective S1PR1 signaling.

\section{Protein Geranylgeranylation Is Required for T Lymphocyte Homing to Secondary Lymphoid Organs}

We next investigated homeostatic $\mathrm{T}$ cell migration in the periphery. Total cellularity of T cells in the blood of Pggt $1 b^{f / / f l}$ $d L c k C r e$ mice was increased while that in the spleen and lymph nodes was decreased compared to Pggt $1 b^{f l / f l}$ littermate controls (Figures 2A,B). The decrease of total T lymphocytes cellularity was more profound in lymph nodes than spleen in Pggt $1 b^{f l / f l}$ $d L c k C r e$ mice (Figures 2B-F). Phenotypically, Pggtlb-deficient $\mathrm{CD}^{+} \mathrm{T}$ cells displayed normal expression of CD62L (data not shown), integrin $\alpha 4 \beta 7$ (Supplementary Figure 1H) and CCR7 (Supplementary Figures 2A,B) compared to wild-type control cells. As expected, the cellularity of $\mathrm{CD}_{1} 9^{+} \mathrm{B}$ cells in both blood and peripheral lymphoid organs were not altered in
Pggt $1 b^{f l / f l} d$ LckCre mice compared with Pggt $1 b^{f l f l}$ littermate controls (Figure 2G). Taken together, these observations suggest that protein geranylgeranylation is intrinsically required for homeostatic T lymphocyte homing to SLOs in the periphery.

\section{Defective in vitro Transmigration and in vivo Homing of Pggt1b-Deficient CD4 ${ }^{+} \mathrm{T}$ Cells}

Lymphocyte migration is critically regulated by chemokinechemokine receptor signaling (2). The impaired T lymphocyte homeostatic homing and thymocyte egress as well as the normal surface expression of S1PR1 on mature thymocytes in Pggtif $f^{f l f l} d$ LckCre mice (Figure 1A) suggest that protein geranylgeranylation is likely required for chemokine-induced migration. To test this, we conducted an in vitro transmigration assay. The C-C motif chemokine ligand 21 (CCL21) is an instrumental chemokine essential for $\mathrm{T}$ lymphocyte homing to SLOs $(2,21) . \mathrm{CD}^{+}$and $\mathrm{CD}^{+} \mathrm{T}$ cells from the spleen of Pggtib fl/fl dLckCre mice displayed substantially diminished 


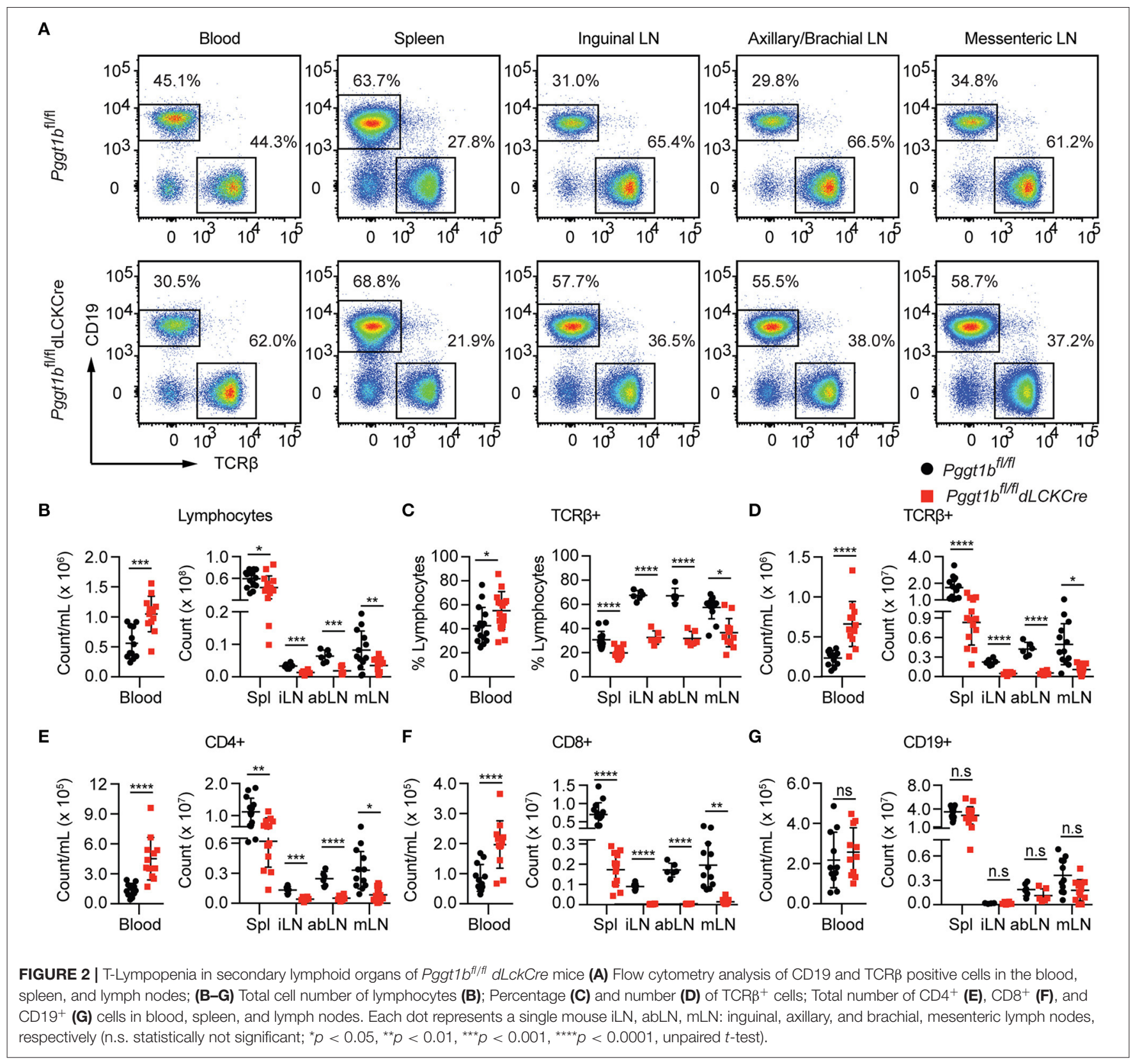

transmigration capacity in response to CCL21 compared to that from wild-type littermate controls (Figures 3A-C). To further assess the capacity of Pggtlb-deficient $\mathrm{CD} 4^{+} \mathrm{T}$ cells in homing to SLOs, a roughly 1:1 mix of differentially labeled purified wildtype and Pggt1b-deficient $\mathrm{CD} 4^{+}$naive $\mathrm{T}$ cells was administered i.v. into recipient $\mathrm{C} 57 \mathrm{BL} / 6$ mice. Consistent with the observation in the steady state, the Pggt1b-deficient $\mathrm{CD}^{+}{ }^{+}$naive $\mathrm{T}$ cells were retained in the blood stream and their capacity to homing to SLOs, more specifically peripheral lymph nodes, was impaired in the recipient mice (Figures 3D-F). The inability of Pggt1bdeficient T cells in response to CCL21 is not due to decreased expression of CCR7 (Supplementary Figures 2A,B) or impaired survival of these cells in vitro (Supplementary Figures 2C,D).
Together, those data indicate that Pggtlb-deficient T cells have an intrinsic transmigration defect in response to chemokine CCL21.

\section{Protein Geranylgeranylation Is Required for Heterotrimeric Small GTPases-Mediated Chemokine Receptor-Proximal Signaling}

The C-C motif chemokine ligand 20 (CCL20) is essential for the migration of Th17 cells into target tissues such as the central nervous system in the context of neuroinflammation (22). Similar to naive T cells, Pggtlb-deficient Th17 cells failed to transmigrate in response to CCL20 despite of CCR6 expression (Supplementary Figures 3A,B). To investigate the underlying 


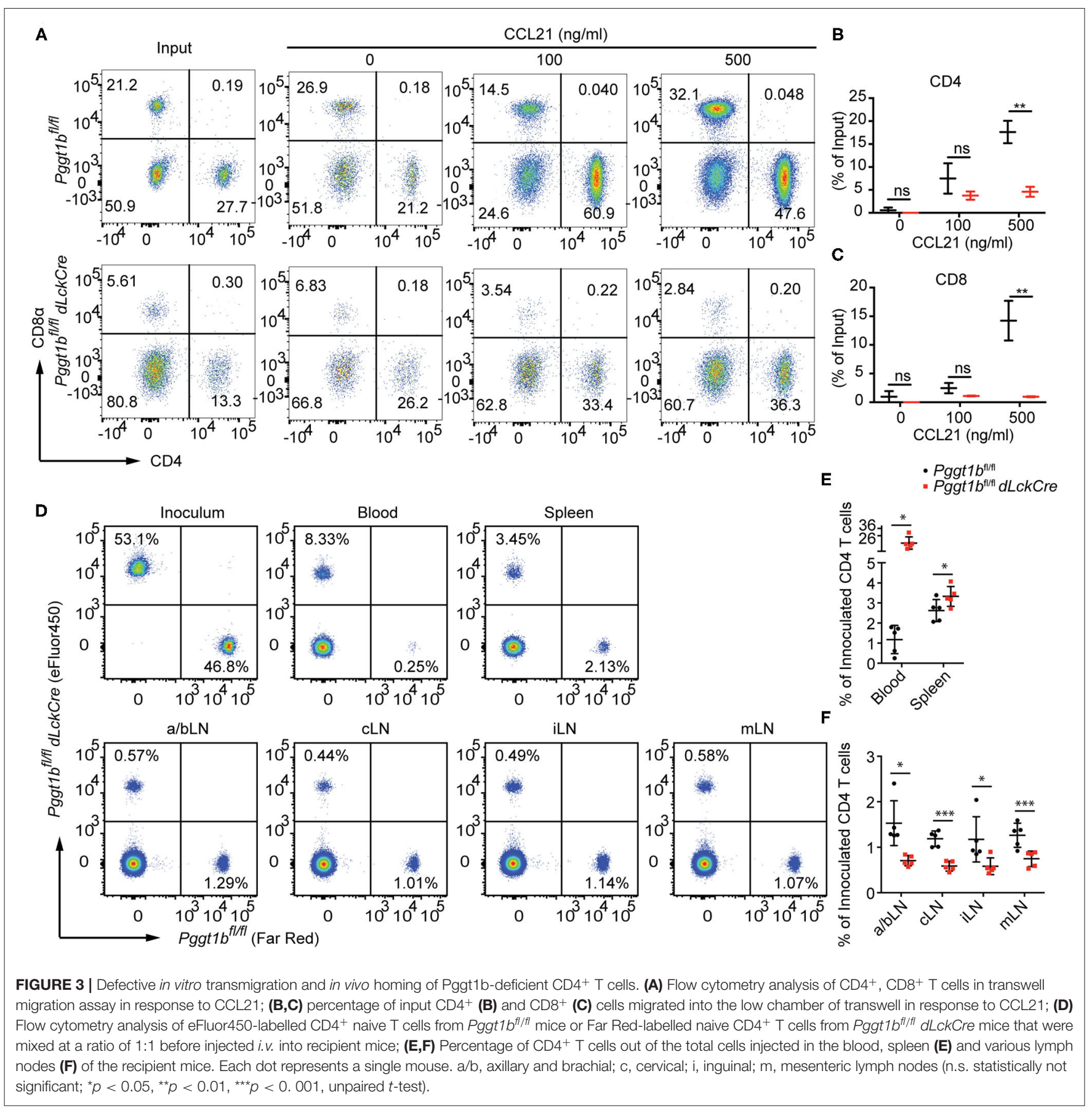

molecular mechanism by which protein geranylgeranylation regulates chemokine receptor signaling, we stimulated in vitro differentiated Th17 cells with CCL20. We chose Th17 cells to further study chemokine receptor signaling since the proliferative Th17 cells are easier than naive $\mathrm{T}$ cells for retroviral infection for genetic complementation approaches. CCL20 stimulation induced robust phosphorylation of Akt, as well as Erk that was impaired in Pggtlb-deficient Th17 cells (Figure 4A). Both Akt and Erk phosphorylation are early signaling events proximal to chemokine receptors necessary for the initiation of cellular signaling cascades required for migration (6). The impaired CCL20-induced Akt and Erk activation in Pggtlb-deficient cells demonstrates that protein geranylgeranylation is indeed required for chemokine receptor proximal signaling.

Chemokine receptors such as CCR6, CCR7, and S1PR1 are G-protein coupled receptors (GPCRs) that use small heterotrimeric GTPases to relay signals initiated at the plasma membrane (23). Among the three heterotrimeric $(\alpha \beta \gamma)$ subunits 


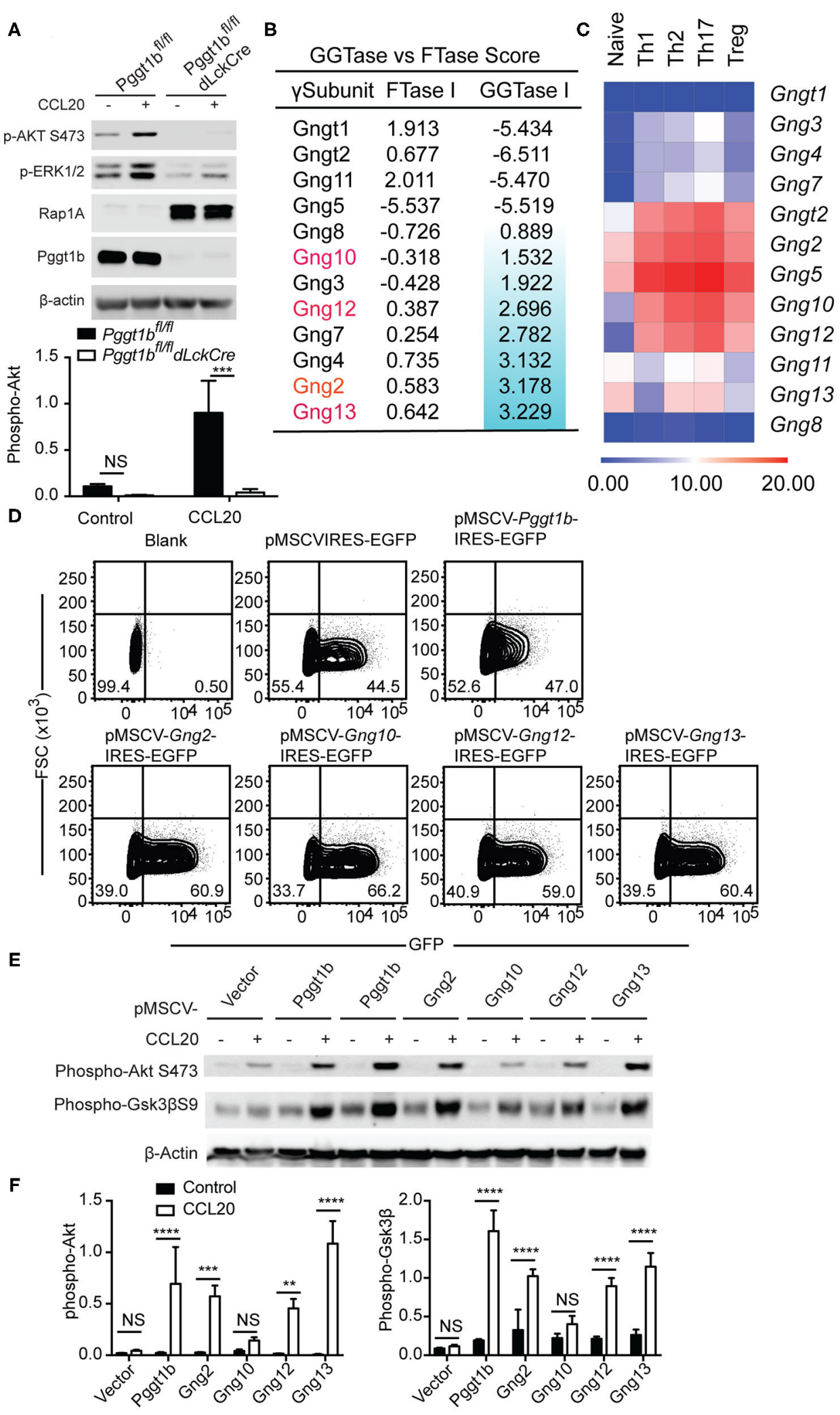

FIGURE 4 | Protein geranylgeranylation is required for heterotrimeric small G-protein mediated GPCR-proximal signaling. (A) Western blot analysis of CCL20-induced phosphorylation of Akt and Erk in Th17 cells and density of phosphor-Akt calculated using ImageJ; (B) FTase I and GGTase I scores of the $12 \gamma$-subunits of the small heterotrimeric GTPases calculated using an algorithm described in the text; (C) Fold change of the expression of the genes encoding the $12 \gamma$-subunits of 
FIGURE 4 | heterotrimeric small GTPase in naive and effector CD4 ${ }^{+}$T cells analyzed by qRT-PCR; (D) Flow cytometry analysis of EGFP expression in Th17 cells infected with retrovirus carrying cDNAs encoding mutant $\gamma$-subunits capable of being farnesylated; (E) Western blot analysis of phosphor-Akt and phosphor-Gsk3ßS9 in Th17 cells described in (D); (F) Density of phosphor-Akt and phosphor-Gsk3 $\beta$ in (E) calculated using Image $\mathrm{J}$ (Results are representatives of three biologically independent experiments, n.s. statistically not significant; ${ }^{* \star} p<0.01,{ }^{* \star *} p<0.001,{ }^{* \star \star *} p<0.0001$ unpaired $t$-test).

of small G-proteins, prenylation [i.e., geranylgeranylation and farnesylation (8)] of the $\gamma$-subunits is required for the plasma membrane localization and functional activity of the small GTPases complex (24). We reasoned that the absence of protein geranylgeranylation would abrogate the plasma membrane localization of $\gamma$-subunits of small GTPases and therefore impair chemokine receptor-proximal signaling.

There are $12 \gamma$-subunits encoded by 12 distinct genes in the murine genome. Precisely, which $\gamma$-subunits mediates $\mathrm{T}$ cell migration remains largely unresolved. We extracted the microarray expression data of the genes encoding the $12 \gamma$ subunits in murine $\alpha \beta$ T cells from the Immgen consortium (25). The array data suggested that only Gng $t 2,2,4,5,10,12$, and 13 were expressed in $\alpha \beta \mathrm{CD}^{+} \mathrm{T}$ cells (Supplementary Figure $3 \mathrm{C}$ ) which we then verified by quantitative RT-PCR. We confirmed that Gng t2, 2, 5, 10, 12, 13 were highly expressed in naive and effector $\mathrm{CD}^{+}{ }^{+} \mathrm{T}$ cell subsets but observed that Gng4 had a lower expression level than predicted by the array data (Figure 4C). We next calculated the prenylation scores of the $12 \gamma$-subunits using a web-based algorithm (26). Of the $6 \gamma$-subunits highly expressed in T cells, Gng13, 2, 12, and 10 have positive geranylgeranylation scores in a descending order (Figure 4B), while Gngt2 and Gng5 have negative geranylgeranylation scores (Figure 4B). We reasoned that the $4 \gamma$-subunits, Gng2, Gng10, Gng12, Gng13, that are highly expressed in $\alpha \beta \mathrm{T}$ cells with positive geranylgeranylation scores are likely the ones that mediate chemokine receptor signaling in $\mathrm{T}$ lymphocytes. To test this hypothesis, we swapped the CAAX (8) motifs in cDNAs encoding Gng2, Gng10, Gng12, Gng13 with sequences encoding a CVSL motif that has been previously shown capable of being farnesylated and restoring the function of Rho GTPases in Pggtlb-deficient macrophages $(10,11,21,27)$. We designated these mutant forms of $\gamma$-subunit as "farnesylable." The cDNAs encoding the "farnesylable" forms of the $4 \gamma$-subunits were cloned into a bi-cistronic retroviral vector expressing an IRES-driven eGFP reporter and transduced into Pggtlb-deficient Th17 cells. Successful transduction was determined by eGFP expression (Figure 4D). Retrovirusmediated ectopic expression of Pggt1b, or the "farnesylable" Gng2, Gng12, Gng13 $\gamma$-subunits resulted in the rescuing of Akt and Gsk3 $\beta$ phosphorylation while expression of Gng10 failed to do so (Figures 4E,F). However, farnesylable Gng13 reconstituted Pggt1b-deficient $\mathrm{T}$ cells failed to migrate in response to CCL20 in vitro, suggesting that protein geranylgeranylation controls additional signaling components in addition to small trimeric GTPases (Supplementary Figure 3D). Since heterotrimeric GTPases directly link GPCR triggering to receptor-proximal signaling, these data suggest that geranylgeranylation likely controls chemokine receptor-proximal signaling through modifying the Gng2, Gng12, and Gng13 $\gamma$-subunits of the heterotrimeric small GTPases.

\section{Pggt1 $b^{f l / f l}$ dLckCre Mice Are Resistant to EAE Induction}

We next tested how protein geranylgeranylation controls effector $\mathrm{T}$ cell function. In a mouse model of experimental autoimmune encephalomyelitis (EAE), encephalitogenic T cells primed in the periphery migrate to the central nervous system to orchestrate pathological changes (28) by recruiting other inflammatory cells such as monocyte-derived dendritic cells (MoDCs) $(29,30)$. EAE resembles many of the immuno-pathological features of human multiple sclerosis and provides an excellent model for testing effector $\mathrm{T}$ cell migration and function. The trafficking of pathogenic immune cells during EAE is subjected to the regulation by chemokine and chemokine receptor signaling $(22,31)$. The S1P1 signaling antagonist Fingolimod has been approved for treating human MS as it sequesters effector T cells within the lymph nodes (32-34).

EAE was induced by immunization of mice with myelin oligodendrocyte glycoprotein (MOG) peptide 35-55 emulsified in complete Freud's adjuvant. Leukocytes were isolated from spinal cords, stained and gated according to a strategy described by Caravagna et al. (17). While Pggt $1 b^{f l / f l}$ mice developed EAE as defined by clinical scores, Pggt $1 b^{f l / f l} d L c k C r e$ mice were resistant to EAE induction (Figure 5A). Consistent with the clinical scores, at the onset (day 14, Supplementary Figure 4) or the peak of the disease (day 19, Figures $5 \mathrm{~B}-\mathrm{E}$ ), CD4 ${ }^{+} \mathrm{T}$ cells as well as the pathogenic Ly6C ${ }^{\text {high }}$ MHC II ${ }^{\text {high }}$ MoDCs $(29,30)$ were recruited into the CNS in $P g g t 1 b^{f l / f l}$ wild-type littermate controls, but not in Pggt $1 b^{f l / f l} d$ LckCre mice.

In EAE, primed encephalitogenic T cells emigrate from SLOs and travel through the circulation to the CNS to orchestrate autoimmunity (35). Emigration of effector T cells from SLOs after priming also depends on chemokine receptor signaling $(2,36)$. Given that there were very few $\mathrm{CD} 4^{+} \mathrm{T}$ cells found in the CNS of $P g g t 1 b^{f l / f l} d L c k C r e$ mice during EAE induction, we reasoned that either the egress from SLOs or their entry into the CNS of effector T cells was impaired in the mutant mice. In steady state, Pggt1b-deficient naive CD62L ${ }^{\text {high }}$ CD $44^{\text {lo }}$ $\mathrm{CD}^{+}$cells accumulated in the circulation and were impaired in homing to SLOs (Supplementary Figures 6A,B). Whereas, the absolute number of CD4 ${ }^{+} \mathrm{CD}_{2} \mathrm{~L}^{\text {lo }} \mathrm{CD} 44^{\text {high }}$ memory/effector (Tem) cells in the blood in Pggt $1 b^{f l / f l} d L c k C r e$ mice was similar to that in wild-type control mice, the number of Tem cells in SLOs seemed to be reduced in Pggt $1 b^{f l / f l} d L c k C r e$ mice than that in wild-type control mice (Supplementary Figures 6C,D). MOG immunization increased the frequency of Tem $\mathrm{CD} 4^{+} \mathrm{T}$ cells in lymph nodes but not spleen in both mouse strains in 


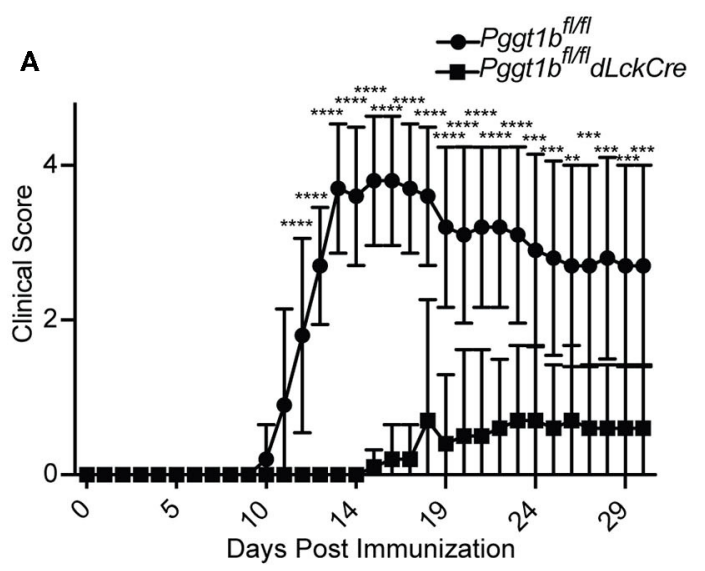

B
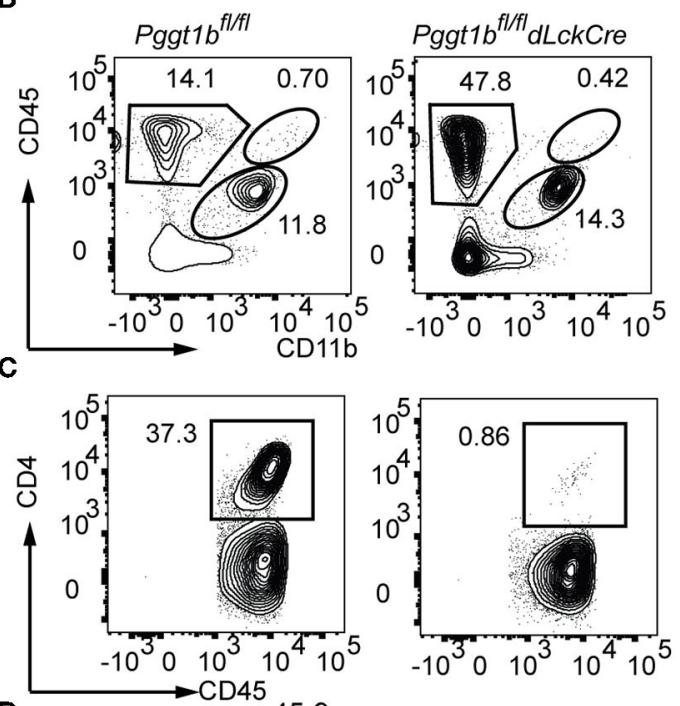

D
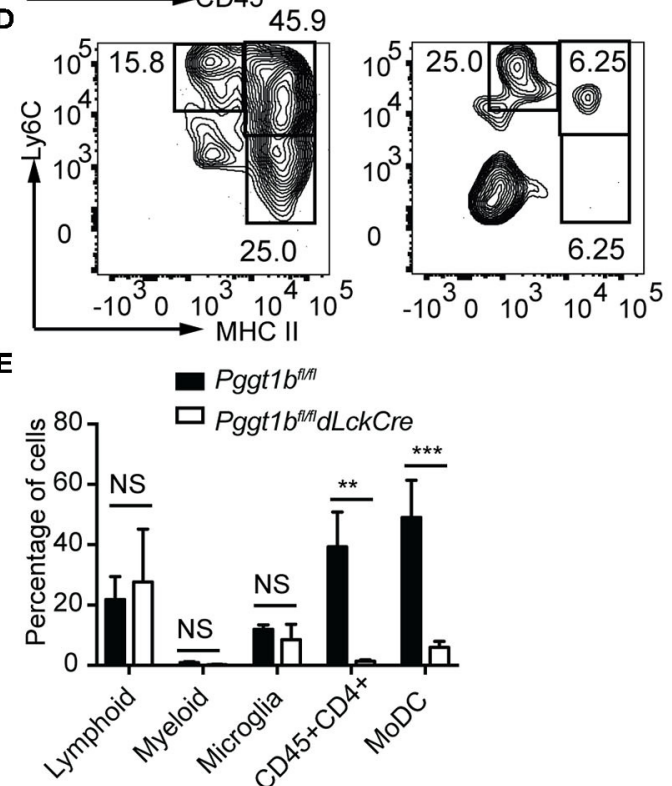

FIGURE 5 | Pggt1 $b^{f l / f l} d$ LckCre mice are resistant to EAE induction. (A) Clinical scores of mice immunized with MOG35-55 peptide emulsified in complete Freud's adjuvant; (B-D) Flow cytometry analysis of spinal cords

(Continued)
FIGURE 5 | leukocytes isolated from mice on day 19 after immunization and stained with antibodies against CD45, CD11b, CD4, Ly6C, Ly6G, CD44,

CD64, and $\mathrm{MHC} \| \mathrm{I}$ and gated according to a strategy described in the text to distinguish myeloid, lymphoid, microglia, CD4 ${ }^{+} \mathrm{T}$ cells, and monocyte-derived dendritic cells (MoDCs); (E) Percentage of lymphoid, myeloid, microglia, CD4 ${ }^{+}$ $T$ cells, and MoDCs in the spinal cord (Results are from two independent biological experiments with a total of 20 mice (10 male, 10 female)) [NS, not significant, ${ }^{* \star} p<0.01,{ }^{\star \star *} p<0.001,{ }^{* * \star *} p<0.0001$, way anova (A), unpaired $t$-test $(\mathbf{E})]$

comparison to steady-state mice (Supplementary Figures 6C,D and Figures $6 \mathrm{C}, \mathrm{D}$ ), indicating that the priming was not substantially affected in the lymph nodes of Pggti $b^{\text {fl/fl }} d L c k C r e$ mice. However, the frequency and number of Tem cells in the blood of Pggtib fl/fl dLckCre mice were significantly lower than those in Pggt1 $b^{f l f l}$ littermate controls (Figures 6A,E) 7 days after immunization. More importantly, MOG35-55-specific CD4 ${ }^{+}$ Tem cells (encephalitogenic T cells) were barely detectable in the blood of Pggt $1 b^{f l / f l} d L c k C r e$ mice after immunization compared with that in wild-type littermate controls (Figures 6B,E). Those observations suggest that protein geranylgeranylation is required for effector $\mathrm{T}$ cell emigration from SLOs in a primary adaptive immune response.

We further determined whether in vitro differentiated Pggt1bdeificient pathogenic Th17 cells could cause EAE. Recipient mice adoptively transferred with Pggtlb-deficient 2D2 (MOGspecific TCR)-transgenic (15) Th17 cells failed to develop EAE, whereas mice received wild-type 2D2-transgenic Th17 cells developed clinical diseases accompanied by severe body weight loss (Supplementary Figure 5).

\section{Pggt1b-Deficient CD4+ Naive T Cells Preferentially Differentiated Into Foxp $3^{+} \mathbf{T}$ Regulatory Cells at the Cost of Th17 Cells in vitro}

Th17 cells play important roles in the host resistance to extracellular pathogens and in the pathogenesis of autoimmune diseases (37). Th17 cell early differentiation is driven by transforming growth factor- $\beta$ (TGF $\beta 1)$ and IL-6 (38-40). When cultured in the presence of TGF $\beta 1$ and IL-6, the differentiation of Th17 cells from Pggtlb-deficient naive $\mathrm{CD}^{+} \mathrm{T}$ cells was impaired compared to that from wild-type controls (Figure 7A). More strikingly, this defect was concomitant with the emergence of iTregs in the culture (Figures 7A,B). In addition to IL17A, mRNA expression of other Th17 signature cytokines were also significantly lower in Pggt1b-deficient Th17 cell cultures than that in wild-type controls (Figure 7C). Th17 cells need exposure to IL-23 to gain pathogenicity in an EAE model (4143). Together with the pro-inflammatory cytokine IL-1, IL23 promotes the differentiation of Th17 cells into GM-CSFproducing effector cells (44) that recruit pathogenic MoDCs into the CNS to cause EAE $(45,46)$. When cultured in the presence of IL-1 and IL-23 or IL-1, IL-6, and IL-23, Pggtlb-deficient $\mathrm{CD}^{+}$naive $\mathrm{T}$ cells were also defective in the differentiation into GM-CSF-producing effector cells in vitro (Figures 7D,E). 

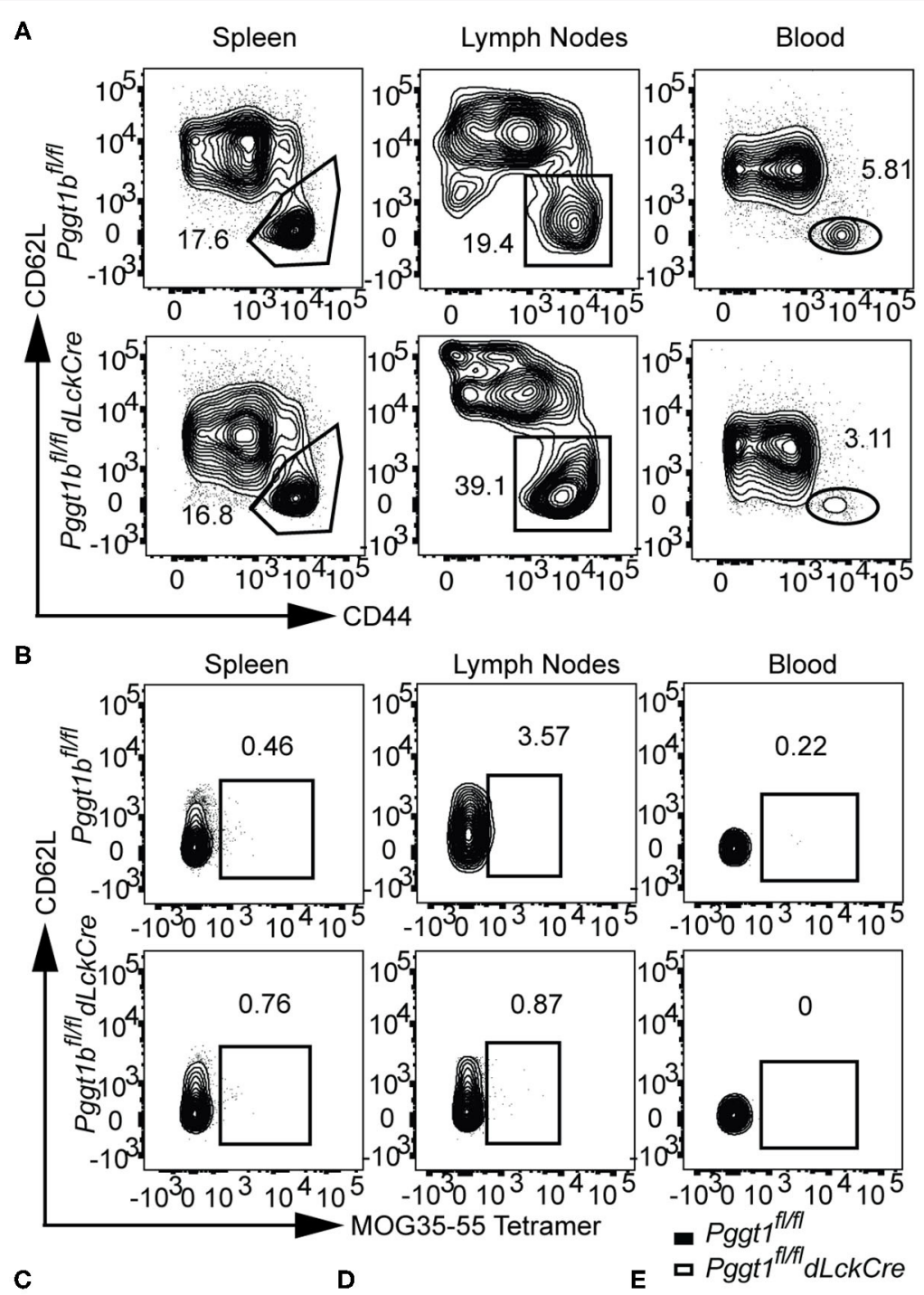

\section{Spleen}

Lymph Nodes

Blood
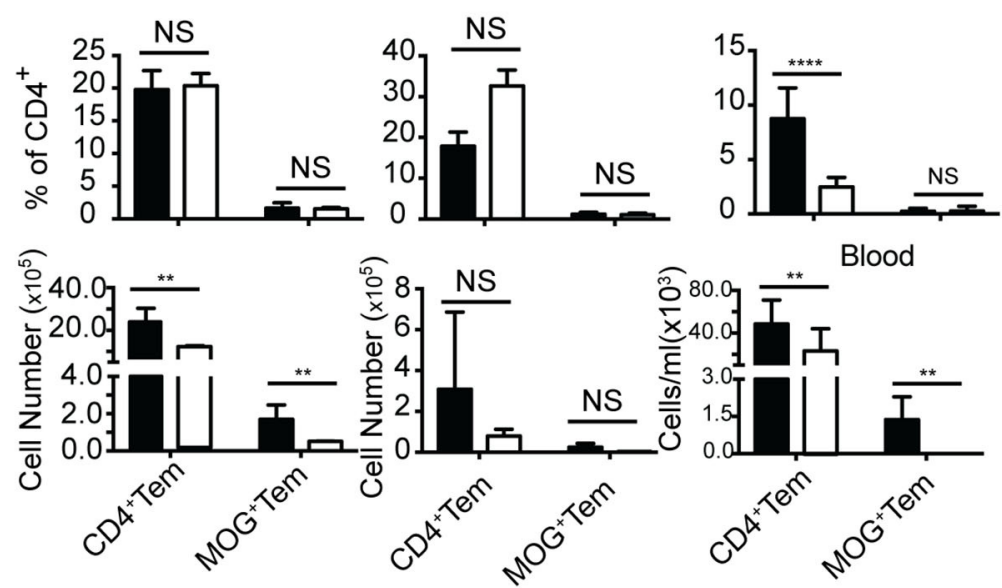

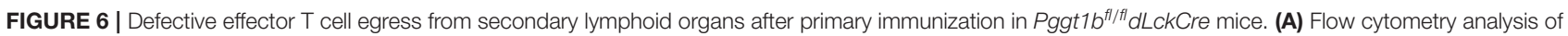
effector (CD44 high, CD62L low) $\mathrm{CD}^{+}{ }^{+} \mathrm{T}$ cells in the spleen, draining lymph nodes and blood 7 days after immunization; (B) Flow cytometry analysis of MOG-specific $\mathrm{CD}^{+}$effector $\mathrm{T}$ cells in spleen, lymph nodes and blood 7 days after immunization; absolute number of $\mathrm{CD} 4^{+}$effector cells and MOG-specific CD4 ${ }^{+}$effector T cells in 
FIGURE 6 | spleen (C), lymph nodes (D), and blood (E). Results are representative of two biologically independent experiments with a total of 16 (8 male, 8 female) mice (NS, not significant, ${ }^{\star \star} p<0.01,{ }^{\star \star *} p<0.001,{ }^{* \star \star \star} p<0.0001$ unpaired $t$-test).

The increased Foxp $3^{+}$iTreg cells found in Th17 cultures prompted us to investigate whether in vitro differentiation of iTregs was also affected by Pggtlb deficiency. Pggtlbdeficient naive $\mathrm{CD}^{+} \mathrm{T}$ cells exhibited significantly enhanced differentiation into $\mathrm{Foxp}^{+}$iTregs in the presence of low concentrations of TGF $\beta 1$ with increased expression of Foxp3 as well as IL2a, but not Ctla4 and Tnfrsf 18 compared with wild-type control cells (Figures 7F,G). In accordance with these findings, IL-6-stimulated phosphorylation of Stat3, a transcription factor essential for Th17 cell differentiation (47, 48), was impaired in Pggtlb-deficient $\mathrm{CD}^{+}$naive $\mathrm{T}$ cells while TGF 1 -induced phosphorylation of Smad2 and Smad3, transcription factors pivotal to iTreg differentiation (49), was enhanced (Supplementary Figures 7A-C). We conclude that protein geranylgeranylation is a critical determinant in the balance of lineage commitment for naive $\mathrm{CD}^{+} \mathrm{T}$ cells to Th17 or iTreg cells in vitro. Nevertheless, the development of nTregs in the thymus of Pggt1bfl/fldLckCre mice was largely unaltered (Supplementary Figure 7D).

\section{DISCUSSION}

Protein geranylgeranylation is a post-translational lipid modification that regulates diverse processes ranging from cell cycle progression to innate immune response. Using a mouse strain with $\mathrm{T}$ cell lineage-specific ablation of the $\beta$-subunit of GGTase-I, we demonstrate that protein geranylgeranylation controls $\mathrm{T}$ cell migration by regulating chemokine-receptorproximal signaling. Protein geranylgeranylation also promotes the development of inflammatory Th17 cells while inhibiting naive $\mathrm{T}$ cells differentiation into Foxp $3^{+}$iTreg cells in vitro.

Migration between different compartments of the thymus is crucially required for thymocyte development (50). Two previous studies $(12,13)$ reported severe lymphopenia in the periphery in Pggt $1 b^{f l / f l} C D 4 C r e$ mice. The CD4-promoter/enhancer/silencerdriven cre induces the deletion of loxp sites-flanked genes with $>90 \%$ efficiency in DP thymocytes (51). DP thymocytes need to migrate from the cortex of thymus to the medulla while continuing maturation into CD4 or CD8 SP thymocytes. This migration is driven by chemokine receptor signaling (52). Given the pivotal role of Pggtlb in chemokine receptor signaling, abrogation of Pggtlb in DP thymocytes would presumably impede the migration of those cells from cortex to medulla and likely impair their maturation. We have established a mouse strain in which cre-mediated deletion of Pggt1b occurs at late stage of thymocyte development by utilizing $d L c k C r e$ transgene (14). Our data showed that cre-mediated deletion of Pggt1b occurs only in a very small fraction of DP thymocytes. Though we observed increased numbers of mature thymocytes in the thymus, a significant number of mature naive $\mathrm{T}$ cells migrated into periphery, presumably before the completion of cre-mediated deletion of Pggtlb as well as a thorough degradation of existing geranylgeranylated proteins. Instead, we observed accumulation of naive $\mathrm{T}$ cells in the blood and a defect of Pggtlb-defcient mature $\mathrm{T}$ cells in homing to SLOs. Thus, our animal model enabled us to study how protein geranylgeranylation regulates the migration and function of mature $\mathrm{T}$ cells in the periphery without severely impeding early thymocyte development.

Lopez-Posadas et al. reported that the majority of Pggtlbdeficient CD4 T cells in Pggt $1 b^{f l / f l} \mathrm{CD} 4 \mathrm{Cre}$ mice displayed an activated phenotype with up-regulation of $\alpha 4 \beta 7$ and CD44 (13) as well as localization to colon with increased expression of inflammatory cytokines that caused colitis (12). However, those phenotypes were not recapitulated in $P g g t 1 b^{f l / f l} d L c k C r e$ mice. Instead, naive Pggtlb-deficient $\mathrm{CD}^{+} \mathrm{T}$ cells from $P g g t 1 b^{f l / f l} d L c k C r e$ mice preferentially differentiated into iTregs at the cost of Th17 cell differentiation in vitro. This discrepancy is likely because deletion of Pggt1b at an early stage of thymocyte development in Pggt $1 b^{f l f f} C D 4 C r e$ mice may have altered the TCR repertoire or property that these $\mathrm{CD}^{+} \mathrm{T}$ cells become colitogenic. While not explored by López-Posadas et al. (12) and $\mathrm{Du}$ et al. (13) in Pggt $1 b^{f l / f l} \mathrm{CD} 4 \mathrm{Cre}$ mice, we observed normal ratio of nTregs in the thymus (Supplementary Figure 7D) and periphery (data not shown) in Pggt $1 b^{f l / f l} d L c k C r e$ mice. The unaffected nTreg development as well as the propensity of naive $\mathrm{T}$ cells to differentiate into iTregs likely helped maintain the immune homeostasis in the colon in Pggt $1 b^{f l / f l} d L c k C r e$ mice.

Chemokine and chemokine receptor signaling guides the migration of lymphocytes which is essential for immune surveillance and successful adaptive immune responses. However, signaling pathways downstream of chemokine receptors remain poorly understood. It is known that protein geranylgeranylation is essential for the function of Rho family small GTPases such as Rac, Rho, and Cdc42 (8, 53), critical players in signaling distal to chemokine receptors. Deficiency of RhoA specifically in $\mathrm{T}$ cells also resulted in reduced $\mathrm{T}$ cell function (54). It has also been reported that protein geranylgeranylation promotes $\mathrm{Cdc} 42$ and Pak signaling and Tiam1 expression in T cells $(13,37)$. However, RhoA, Pak and Tiam1-dependent signaling events are distal to chemokinereceptor and secondary to the receptor-proximal signaling. Data presented here demonstrate that, in addition to the above mentioned distal signaling events, protein geranylgeranylation also controls the early signaling events immediately downstream of chemokine receptors through modification of the $\gamma$-subunits of heterotrimeric small GTPases.

Prenylation of the $\gamma$-subunit is essential for the plasma membrane-localization and signal-relaying function of heterotrimeric small GTPases (24). Among the $12 \gamma$-subunits, eight of them are prone to protein geranylgeranylation; three of them are likely to be farnesylated and one can be neither farnesylated nor geranylgeranylated based on the 

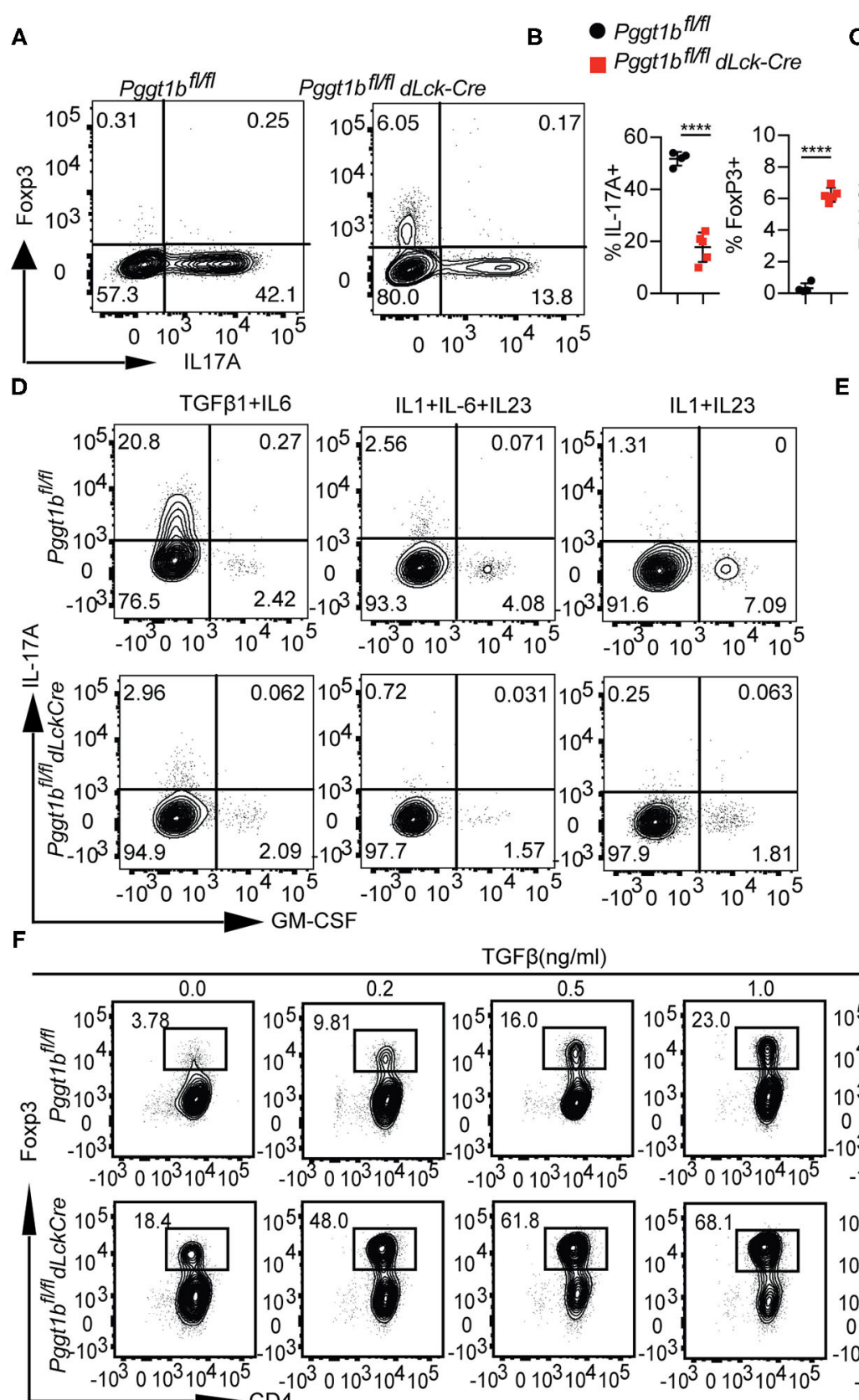

G

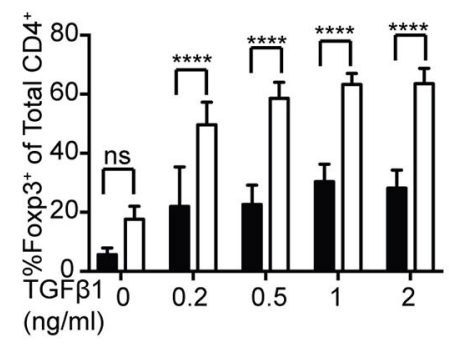

TGF $\beta(\mathrm{ng} / \mathrm{ml})$

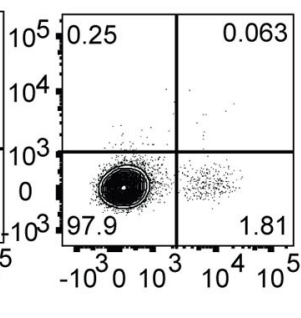

$-10^{3} 010^{3} 10^{4} 10^{5}$

$-10^{3} 010^{3} 10^{4} 10^{5}$

$-10^{3} 010^{3} 10^{4} 10^{5}$
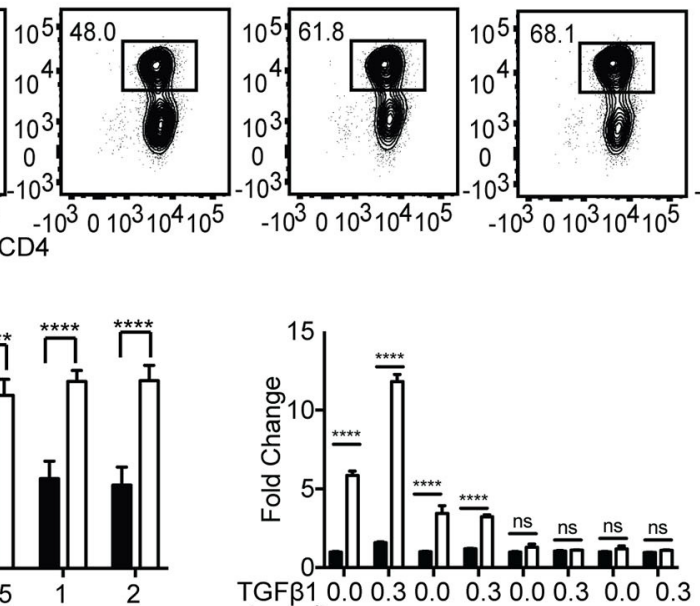

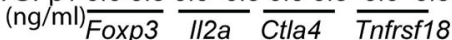

C $\operatorname{Pggt1b^{fl/fl}}$

ㅁ Pggt $1 b^{f / f f l} d L c k$-Cre

2.5 Th17-signature genes

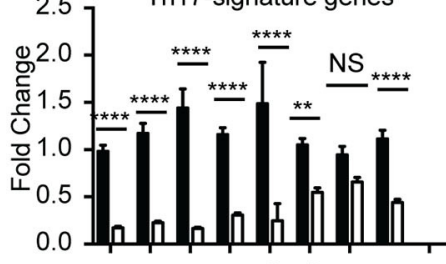

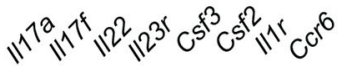

E
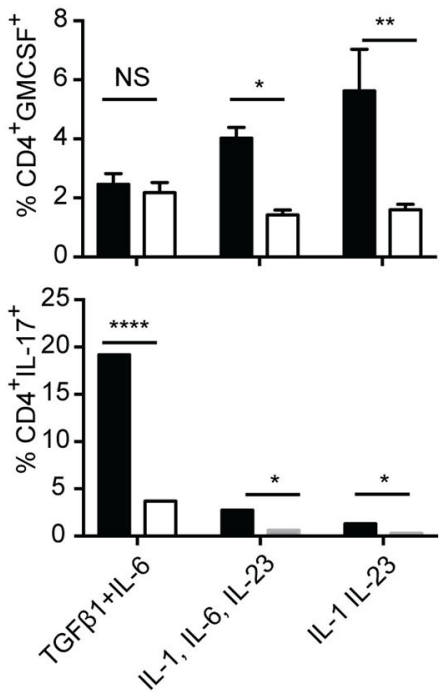

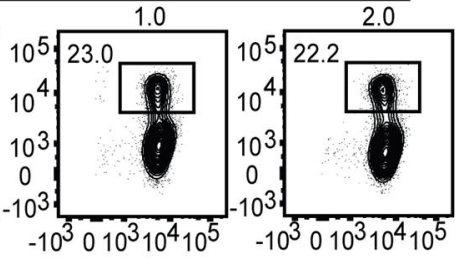

$-10^{3} 010^{3} 10^{4} 10^{5}$

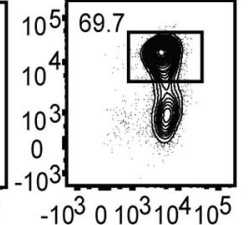

FIGURE 7 | Pggt1b-deficient naive T cells are predisposed to differentiate into T regulatory cells in vitro. (A) Flow cytometry analysis of the expression of Foxp3 and IL-17A in cells cultured in the presence of plate-bound anti-CD3 and anti-CD28 antibodies and TGF31 and IL-6 for 72 h; (B) Percentage of IL-17A+ or Foxp3+ CD4+ cells in the culture described in (A); (C) Fold change of Th17 signature cytokines in cells described in (A) analyzed by qRT-PCR; (D) Flow cytometry analysis of 
FIGURE 7 | GM-CSF+ and IL- $17^{+}$CD4 ${ }^{+}$T cells in cells cultured in the presence of TGF 31 and IL-6, IL-1, IL-6, and IL-23 or IL-1 IL-23; (E) Percentage of GM-CSF+ and IL-17A+ $\mathrm{CD}^{+}+\mathrm{T}$ cells in cultures described in (D); (F) Flow cytometry analysis of naive $\mathrm{T}$ cells $72 \mathrm{~h}$ after cultured in the presence of plate-bound anti-CD3 and anti-CD28 antibody and different concentrations of TGF 1 ; (G) percentage of Foxp3+ CD4+ T cells in the culture described in (F) and qRT-PCR analysis of the expression T regulatory cell genes in cell cultures described in (F). Results are representative of three independent biological experiments [n.s. statistically not significant; ${ }^{*} p<0.05,{ }^{* \star} p<0.01,{ }^{* \star *} p<0.001,{ }^{\star \star \star *} p<0.0001$, two-way anova (C), unpaired $t$-test (G)].

web-based prenylation scoring algorithm (26). It has been reported that abrogation of farnesylation in $\mathrm{T}$ cells does not affect thymocyte egress (13). However, it is highly likely that farnesylation may play a role in regulating the migration of immune cells other than $\mathrm{T}$ lymphocytes. It is also of note that when farnesylation is inhibited, some farnesylation-prone substrate can be modified by protein geranylgeranylation and become fully functional (55) and this may impede the study of intrinsic role of protein farnesylation in cell migration or other physiological processes. Nevertheless, our results support a critical role of protein geranylgeranylation in regulating mature T lymphocyte migration.

The high endothelial venules (HEV), a highly specialized type of post capillary endothelium within the paracortical regions, play important role in lymphocyte entry into lymph nodes (56). Transmigration of T cells through HEV to enter lymph nodes is a regulated process that is dependent on chemokine-chemokine receptor signaling. In contrast, there is no HEV in spleen. T cells enter the red pulp of the spleen where the central arterioles are open through an unregulated, passive process. Our results showed that more Pggtlb-deficient T cells homed to spleen than the wild-type control cells in the in vivo homing assay. This is likely because Pggt $1 \mathrm{~b}$-deficient $\mathrm{T}$ cells can enter the spleen red pulp as efficient as wild-type cells. The increased number of Pggtlb-deficient $\mathrm{T}$ cells in the circulation might have also enhanced the effect.

Given the fact that Pggt1b-deficient naive T cells homing to SLOs is impaired, the efficiency of $\mathrm{T}$ lymphocyte priming after immunization would also be adversely affected in Pggtif fl/fl $d L c k C r e$ mice. This is one of the limitations of using the current animal model to study immunization efficiency. However, the post-immunization frequency of Tem cells in SLOs were similar between Pggt $1 b^{f l / f l} d L c k C r e$ mice and the wild-type littermate controls (Figures 6C,D) although the absolute numbers were significantly lower in Pggtib fl/fldLckCre mice. This could be the result of combined effects of the impaired entry of naive $\mathrm{T}$ cells as well as the deficient egress of effector $\mathrm{T}$ cells in a dynamic environment. In addition, protein geranylgeranylation is also likely to impact the priming efficacy by affecting the interaction between naive $\mathrm{T}$ cells and antigen presenting cells in SLOs since Rho family small GTPases, important regulators of immunological synapse formation (16), are prototypes of GGTase-I substrates. However, the result that in vitro differentiated 2D2-transgenic Pggt1b-deficient Th17 cells, which by-passed the in vivo priming process, failed to induce EAE in recipient mice, indicates that protein geranylgeranylation controls immune responses beyond priming in SLOs. Given the intrinsic defect of naive Pggtlb-deficint T cells in Th17 cell differentiation and transmigration, $\alpha 47$ the observed phenotype of decreased EAE score in Pggti $b^{f l f l} d L c k C r e$ mice is likely due to the combined effects of impaired migration and compromised effector function of Th17 cells. Future experiments are warranted to disentangle those two impacts caused by Pggtlb-deficiency.

$\mathrm{T}$ cell egress from SLOs also depends on S1PR1 signaling (36). S1PR1 is a GPCR that also depends on trimeric small GTPases for signal transduction which requires protein geranylgeranylation. Since integrin activation is downstream of chemokine receptor signaling in the inside-out signaling cascade, a defective chemokine receptor signaling would inevitably lead to compromised integrin activation. The S1P1 signaling antagonist Fingolimod has been approved for treating human MS as it sequesters effector $\mathrm{T}$ cells within the lymph nodes (3234, 57). Therefore, the EAE model with Pggt $1 b$ fl/fl dLckCre mice resembles those of mice treated with S1P1 functional antagonist. The observation that there was substantial number of effector T cells in SLOs after immunization, the significantly decreased number of effector $\mathrm{T}$ cells in the blood, and the near absence of MOG-specific effector T cells in the circulation despite of the presence of these cells in SLOs in Pggt $1 b^{f l / f l}$ dLckCre mice, combined with the fact that effector $\mathrm{T}$ cell emigration from SLOs depends on S1PR1 signaling, strongly suggested that protein geranylgeranylation is likely required for the emigration of effector $\mathrm{T}$ cells into the circulation after primary immunization.

Protein geranylgeranylation utilizes geranylgeranyl pyrophosphate (GGPP) as a substrate. GGPP is an intermediate product of the cholesterol-synthesizing mevalonate pathway. Therefore, our finding revealed a metabolic control of lymphocyte migration and effector function by a fundamental metabolic pathway. Elucidation of the molecular mechanisms by which lipid metabolism controls immune cell function may provide new opportunity in managing immune-mediated diseases or for manipulations to enhance immune cell function in treating cancer.

\section{DATA AVAILABILITY STATEMENT}

The raw data supporting the conclusions of this article will be made available by the authors, without undue reservation.

\section{ETHICS STATEMENT}

The animal study was reviewed and approved by IACUC, Duke University. 


\section{AUTHOR CONTRIBUTIONS}

DW conceived the research. DW, GS, JG, and GEH contributed to experimental design and evaluation of results. GS, JG, EP, QD, JJZ, GS, and CW conducted experiments. JZ and H-IH helped with flow panel set up and flow cytometry data analysis. DW drafted the manuscript. GS and EP worked on editing, revising, and finalizing the manuscript. All authors contributed to the article and approved the submitted version.

\section{FUNDING}

This work was supported in part by 1R01AI110695 to DW. Additional support was provided by NIH R01-AI45930 (awarded to GEH).

\section{ACKNOWLEDGMENTS}

We thank Ms. Catherine Sweeney for maintaining the animal colony and help with the EAE experiments, Dr. Shigao Yang for help with the immunoblot, and Yirong $\mathrm{Xu}$ for help with the flow cytometry experiments and animal colony maintenance. We are grateful to Dr. Mari Shinohara and her lab members Elizabeth Deerhake and William Barclay for technical help with the EAE model and CNS leukocyte isolation and flow cytometry analysis.

\section{SUPPLEMENTARY MATERIAL}

The Supplementary Material for this article can be found online at: https://www.frontiersin.org/articles/10.3389/fimmu. 2021.641188/full\#supplementary-material

Supplementary Figure 1 | Establishment of the Pggt $1 b^{f / / f l} d L c k C r e$ mouse strain. (A) Flow cytometry of total thymocytes from Pggt $1 b^{f / f f l}$ tdTomato ${ }^{\text {Stopfloxed }} d$ LckCre mice; (B,C) Expression of tdTomato in different subpopulations of thymocytes as described in (A); (D) quantitative RT-PCR analysis of Pggt1b expression in FACS-sorted subpopulations of thymocytes as described in (A); (E) Immunoblot of total thymocyte lysate; (F,G) quantitative RT-PCR analysis $(\mathbf{F})$ and immunoblot (G) of Pggt1b in CD4+ Naive T cells from spleen; (H) Flow cytometry analysis of the expression of integrin $\alpha 4 \beta 7$ on $\mathrm{CD}^{+}{ }^{+}$naive $T$ cells (data are representative of

\section{REFERENCES}

1. Cyster JG. Chemokines and cell migration in secondary lymphoid organs. Science. (1999) 286:2098-102. doi: 10.1126/science.286.5447. 2098

2. Griffith JW, Sokol CL, Luster AD. Chemokines and chemokine receptors: positioning cells for host defense and immunity. Annu Rev Immunol. (2014) 32:659-702. doi: 10.1146/annurev-immunol-032713-12 0145

3. Matloubian M, Lo CG, Cinamon G, Lesneski MJ, Xu Y, Brinkmann $\mathrm{V}$, et al. Lymphocyte egress from thymus and peripheral lymphoid organs is dependent on S1P receptor 1. Nature. (2004) 427:355-60. doi: 10.1038/nature02284

4. Masopust D, Schenkel JM. The integration of T cell migration, differentiation and function. Nat Rev Immunol. (2013) 13:309-20. doi: 10.1038/nri3442 results of at least two independent biological experiments, n.s. statistically not significant; ${ }^{* * *} p<0.001,{ }^{* * * *} p<0.0001$ unpaired $t$-test)

Supplementary Figure 2 | CCR7 expression and in vitro survival of Pggt1b-deficient naive T cells. (A) Flow cytometry analysis of CCR7 expression on naive CD4 ${ }^{+}$T cells; (B) Mean fluorescence intensity of CCR7 described in (A); (C) percentage and (D) number of viable naive $\mathrm{CD} 4^{+} \mathrm{T}$ cells cultured in vitro in the absence or presence of mIL-7 (Results are representatives of at least two biologically independent experiments. n.s. statistically not significant; ${ }^{*} p<0.05$, ${ }^{* *} p<0.01,{ }^{* * *} p<0.001,{ }^{* * * *} p<0.0001$, unpaired $t$-test).

Supplementary Figure 3 | Transmigration and CCR6 expression of Th17 cells and the expression of genes encoding the $\gamma$-subunits of heterotrimeric small GTPases in $\alpha \beta$ T cells. (A) Percentage of input of Th17 cells transmigrated into the low chamber in response to CCL20 in transmigration assay; (B) Overlay of histogram of flow cytometry analysis of the expression of CCR6 on in vitro derived Th17 cells; (C) Array expression data were extracted from the Immgen consortium website and converted into logarithmic fold of changes and heatmap were generated using Morpheus web-based tools created by Broad Institute (https:// software.broadinstitute.org/morpheus/); (D) percentage of input of GFP-positive, vector or Gng13-transduced Pggt1b-deficient Th17 cells transmigrated into the lower chamber in response to $500 \mathrm{ng} / \mathrm{ml}$ CCL20.

Supplementary Figure 4 | Defective CD4 and monocyte-derived DC infiltration into the CNS of Pggt $1 b^{f l / f l}$ dLckCre mice on day 14 after immunization. Mice were immunized as described in Figure 5, (A-C) Flow cytometry analysis of spinal cords leukocytes harvest on day 19 after immunization that were stained with antibodies against CD45, CD11b, CD4, Ly6C, Ly6G, CD44, CD64, and MHC ॥ and gated according to a strategy described in the text to distinguish myeloid, lymphoid, microglia, CD4 ${ }^{+}$T cells, and monocyte-derived dendritic cells (MoDCs); (D) Percentage of lymphoid, myeloid, microglia, CD4+, and MoDCs in the spinal cord (Results are from two independent biological experiments with a total of 20 mice (10 male, 10 female) (NS, not significant, ${ }^{*} p<0.05$, ${ }^{* *} p<0.01$, unpaired $t$-test).

Supplementary Figure $\mathbf{5}$ | Adoptively transferred 2D2-transgenic Pggt1b-deficient Th17 cells failed to induce EAE in recipient mice. (A) Clinical score of mice receiving in vitro differentiated inflammatory 2D2-transgenic Th17 cells; (B) Body weight change of mice described in (A).

Supplementary Figure 6 | Naive and effector/memory CD4+ T cells in the periphery. Percentage and number of naive $(\mathbf{A}, \mathbf{B})$ and effector/memory $(\mathbf{C}, \mathbf{D})$ $\mathrm{CD}^{+}{ }^{+} \mathrm{T}$ cells in blood, spleen, inguinal (iLN), auxiliary and brachial (a/bLN) lymph nodes (Each dot represents an individual mouse, ns, not significant, ${ }^{*} p<0.05$, ${ }^{* *} p<0.01,{ }^{* * *} p<0.001$, unpaired $t$-test).

Supplementary Figure 7 | Impaired IL-6-induced Stat3 phosphorylation and enhanced TGF $\beta 1$-induced Smad2 and Smad3 phosphorylation in Pggt1b-deficient naive CD4+ T cells. (A) Immuno-blot of naive CD4 ${ }^{+} \mathrm{T}$ cells stimulated with IL-6 with antibodies indicated in the figure; (B) Image $\mathrm{J}$ calculation of the phosphor-Stat3 as indicated in (A); (C) Western blot of phosphor-Smad2 and Smad3 of $\mathrm{CD}^{+}{ }^{+}$naive T cells after TGF $\beta 11$ stimulation; (D) Flow cytometry analysis of thymic $T$ regulatory cells.

5. von Andrian UH, Mackay CR. T-cell function and migration. Two sides of the same coin. $N$ Engl J Med. (2000) 343:102034. doi: 10.1056/NEJM200010053431407

6. Kinashi T. Intracellular signalling controlling integrin activation in lymphocytes. Nat Rev Immunol. (2005) 5:546-59. doi: 10.1038/nri1646

7. Bargatze RF, Butcher EC. Rapid G protein-regulated activation event involved in lymphocyte binding to high endothelial venules. J Exp Med. (1993) 178:367-72. doi: 10.1084/jem.178.1.367

8. Zhang FL, Casey PJ. Protein prenylation: molecular mechanisms and functional consequences. Annu Rev Biochem. (1996) 65:24169. doi: 10.1146/annurev.bi.65.070196.001325

9. Sjogren AK, Andersson KM, Liu M, Cutts BA, Karlsson C, Wahlstrom AM, et al. GGTase-I deficiency reduces tumor formation and improves survival in mice with K-RAS-induced lung cancer. J Clin Invest. (2007) 117:1294304. doi: $10.1172 /$ JCI30868 
10. Akula MK, Shi M, Jiang Z, Foster CE, Miao D, Li AS, et al. Control of the innate immune response by the mevalonate pathway. Nat Immunol. (2016) 17:922-9. doi: 10.1038/ni.3487

11. Yang S, Harding AT, Sweeney C, Miao D, Swan G, Zhou C, et al. Control of antiviral innate immune response by protein geranylgeranylation. Sci Adv. (2019) 5:eaav7999. doi: 10.1126/sciadv.aav7999

12. Lopez-Posadas R, Fastancz P, Martinez-Sanchez LDC, PanteleevIvlev J, Thonn V, Kisseleva $\mathrm{T}$, et al. Inhibiting PGGT1B disrupts function of RHOA, resulting in T-cell expression of integrin alpha4beta7 and development of colitis in mice. Gastroenterology. (2019) 157:1293-309. doi: 10.1053/j.gastro.2019.07.007

13. Du X, Zeng H, Liu S, Guy C, Dhungana Y, Neale G, et al. Mevalonate metabolism-dependent protein geranylgeranylation regulates thymocyte egress. J Exp Med. (2020) 217:e20190969. doi: 10.1084/jem.20190969

14. Zhang DJ, Wang Q, Wei J, Baimukanova G, Buchholz F, Stewart AF, et al. Selective expression of the Cre recombinase in late-stage thymocytes using the distal promoter of the Lck gene. J Immunol. (2005) 174:672531. doi: 10.4049/jimmunol.174.11.6725

15. Bettelli E, Pagany M, Weiner HL, Linington C, Sobel RA, Kuchroo VK. Myelin oligodendrocyte glycoprotein-specific T cell receptor transgenic mice develop spontaneous autoimmune optic neuritis. J Exp Med. (2003) 197:107381. doi: $10.1084 /$ jem.20021603

16. Manglani M, Gossa S, McGavern DB. Leukocyte isolation from brain, spinal cord, and meninges for flow cytometric analysis. Curr Protoc Immunol. (2018) 121:e44. doi: 10.1002/cpim.44

17. Caravagna C, Jaouen A, Desplat-Jego S, Fenrich KK, Bergot E, Luche $\mathrm{H}$, et al. Diversity of innate immune cell subsets across spatial and temporal scales in an EAE mouse model. Sci Rep. (2018) 8:5146. doi: 10.1038/s41598-018-22872-y

18. Jordan M, Kohne C, Wurm FM. Calcium-phosphate mediated DNA transfer into HEK-293 cells in suspension: control of physicochemical parameters allows transfection in stirred media. Transfection and protein expression in mammalian cells. Cytotechnology. (1998) 26:39-47. doi: 10.1023/A:1007917318181

19. Madisen L, Zwingman TA, Sunkin SM, Oh SW, Zariwala HA, Gu H, et al. A robust and high-throughput Cre reporting and characterization system for the whole mouse brain. Nat Neurosci. (2010) 13:133-40. doi: 10.1038/nn.2467

20. Allende ML, Dreier JL, Mandala S, Proia RL. Expression of the sphingosine 1phosphate receptor, S1P1, on T-cells controls thymic emigration. J Biol Chem. (2004) 279:15396-401. doi: 10.1074/jbc.M314291200

21. Manzo A, Bugatti S, Caporali R, Prevo R, Jackson DG, Uguccioni M, et al. CCL21 expression pattern of human secondary lymphoid organ stroma is conserved in inflammatory lesions with lymphoid neogenesis. Am J Pathol. (2007) 171:1549-62. doi: 10.2353/ajpath.2007.061275

22. Reboldi A, Coisne C, Baumjohann D, Benvenuto F, Bottinelli D, Lira S, et al. C$\mathrm{C}$ chemokine receptor 6-regulated entry of TH-17 cells into the CNS through the choroid plexus is required for the initiation of EAE. Nat Immunol. (2009) 10:514-23. doi: 10.1038/ni.1716

23. Oldham WM, Hamm HE. Heterotrimeric G protein activation by G-protein-coupled receptors. Nat Rev Mol Cell Biol. (2008) 9:60-71. doi: 10.1038/nrm2299

24. Marrari Y, Crouthamel M, Irannejad R, Wedegaertner PB. Assembly and trafficking of heterotrimeric G proteins. Biochemistry. (2007) 46:766577. doi: $10.1021 /$ bi700338m

25. Mingueneau M, Kreslavsky T, Gray D, Heng T, Cruse R, Ericson J, et al. The transcriptional landscape of $\alpha \beta \mathrm{T}$ cell differentiation. Nat Immunol. (2013) 14:619-32. doi: 10.1038/ni.2590

26. Maurer-Stroh S, Eisenhaber F. Refinement and prediction of protein prenylation motifs. Genome Biol. (2005) 6:R55. doi: 10.1186/gb-2005-6-6-r55

27. Khan OM, Ibrahim MX, Jonsson IM, Karlsson C, Liu M, Sjogren AK, et al. Geranylgeranyltransferase type I (GGTase-I) deficiency hyperactivates macrophages and induces erosive arthritis in mice. J Clin Invest. (2011) 121:628-39. doi: 10.1172/JCI43758

28. Croxford AL, Kurschus FC, Waisman A. Mouse models for multiple sclerosis: historical facts and future implications. Biochim Biophys Acta. (2011) 1812:177-83. doi: 10.1016/j.bbadis.2010.06.010

29. Clarkson BD, Walker A, Harris MG, Rayasam A, Sandor M, Fabry Z. CCR2dependent dendritic cell accumulation in the central nervous system during early effector experimental autoimmune encephalomyelitis is essential for effector T cell restimulation in situ and disease progression. J Immunol. (2015) 194:531-41. doi: 10.4049/jimmunol.1401320

30. Yamasaki R, Lu H, Butovsky O, Ohno N, Rietsch AM, Cialic R, et al Differential roles of microglia and monocytes in the inflamed central nervous system. J Exp Med. (2014) 211:1533-49. doi: 10.1084/jem.20132477

31. Villares R, Cadenas V, Lozano M, Almonacid L, Zaballos A, Martinez $\mathrm{AC}$, et al. CCR6 regulates EAE pathogenesis by controlling regulatory CD4+ T-cell recruitment to target tissues. Eur J Immunol. (2009) 39:167181. doi: 10.1002/eji.200839123

32. Chiba K, Yanagawa Y, Masubuchi Y, Kataoka H, Kawaguchi T, Ohtsuki $\mathrm{M}$, et al. FTY720, a novel immunosuppressant, induces sequestration of circulating mature lymphocytes by acceleration of lymphocyte homing in rats. I. FTY720 selectively decreases the number of circulating mature lymphocytes by acceleration of lymphocyte homing. J Immunol. (1998) 160:5037-44. doi: 10.1046/j.1365-2567.1998.00639.x

33. Suzuki S, Kakefuda T, Amemiya H, Chiba K, Hoshino Y, Kawaguchi T, et al. An immunosuppressive regimen using FTY720 combined with cyclosporin in canine kidney transplantation. Transpl Int. (1998) 11:95101. doi: 10.1007/s001470050111

34. Yanagawa Y, Masubuchi Y, Chiba K. FTY720, a novel immunosuppressant, induces sequestration of circulating mature lymphocytes by acceleration of lymphocyte homing in rats III. Increase in frequency of CD62L-positive T cells in Peyer's patches by FTY720-induced lymphocyte homing. Immunology. (1998) 95:591-4.

35. Codarri L, Greter M, Becher B. Communication between pathogenic T cells and myeloid cells in neuroinflammatory disease. Trends Immunol. (2013) 34:114-9. doi: 10.1016/j.it.2012.09.007

36. Benechet AP, Menon M, Xu D, Samji T, Maher L, Murooka TT, et al. T cellintrinsic S1PR1 regulates endogenous effector T-cell egress dynamics from lymph nodes during infection. Proc Natl Acad Sci USA. (2016) 113:21827. doi: $10.1073 /$ pnas. 1516485113

37. Bedoya SK, Lam B, Lau K, Larkin J III. Th17 cells in immunity and autoimmunity. Clin Dev Immunol. (2013) 2013:986789. doi: 10.1155/2013/986789

38. Bettelli E, Carrier Y, Gao W, Korn T, Strom TB, Oukka M, et al. Reciprocal developmental pathways for the generation of pathogenic effector TH17 and regulatory T cells. Nature. (2006) 441:235-8. doi: 10.1038/nature04753

39. Harrington LE, Mangan PR, Weaver CT. Expanding the effector CD4 T-cell repertoire: the Th17 lineage. Curr Opin Immunol. (2006) 18:34956. doi: 10.1016/j.coi.2006.03.017

40. Veldhoen M, Hocking RJ, Atkins CJ, Locksley RM, Stockinger B. TGFbeta in the context of an inflammatory cytokine milieu supports de novo differentiation of IL-17-producing T cells. Immunity. (2006) 24:17989. doi: 10.1016/j.immuni.2006.01.001

41. McGeachy MJ, Bak-Jensen KS, Chen Y, Tato CM, Blumenschein W, McClanahan T, et al. TGF-beta and IL- 6 drive the production of IL-17 and IL-10 by T cells and restrain T(H)-17 cell-mediated pathology. Nat Immunol. (2007) 8:1390-7. doi: 10.1038/ni1539

42. Codarri L, Gyulveszi G, Tosevski V, Hesske L, Fontana A, Magnenat L, et al. RORgammat drives production of the cytokine GM-CSF in helper T cells, which is essential for the effector phase of autoimmune neuroinflammation. Nat Immunol. (2011) 12:560-7. doi: 10.1038/ni.2027

43. Gaffen SL, Jain R, Garg AV, Cua DJ. The IL-23-IL-17 immune axis: from mechanisms to therapeutic testing. Nat Rev Immunol. (2014) 14:585600. doi: $10.1038 /$ nri3707

44. El-Behi M, Ciric B, Dai H, Yan Y, Cullimore M, Safavi F, et al. The encephalitogenicity of $\mathrm{T}(\mathrm{H}) 17$ cells is dependent on IL-1- and IL-23induced production of the cytokine GM-CSF. Nat Immunol. (2011) 12:56875. doi: 10.1038/ni.2031

45. Becher B, Tugues S, Greter M. GM-CSF: from growth factor to central mediator of tissue inflammation. Immunity. (2016) 45:963-73. doi: 10.1016/j.immuni.2016.10.026

46. Komuczki J, Tuzlak S, Friebel E, Hartwig T, Spath S, Rosenstiel P, et al. Fate-mapping of GM-CSF expression identifies a discrete subset of inflammation-driving $\mathrm{T}$ helper cells regulated by cytokines IL-23 and IL-1beta. Immunity. (2019) 50:1289-304 e6. doi: 10.1016/j.immuni.2019.0 4.006 
47. Yang XO, Pappu BP, Nurieva R, Akimzhanov A, Kang HS, Chung Y, et al. $\mathrm{T}$ helper 17 lineage differentiation is programmed by orphan nuclear receptors ROR alpha and ROR gamma. Immunity. (2008) 28:2939. doi: 10.1016/j.immuni.2007.11.016

48. Durant L, Watford WT, Ramos HL, Laurence A, Vahedi G, Wei L, et al. Diverse targets of the transcription factor STAT3 contribute to $\mathrm{T}$ cell pathogenicity and homeostasis. Immunity. (2010) 32:60515. doi: 10.1016/j.immuni.2010.05.003

49. Gu AD, Wang Y, Lin L, Zhang SS, Wan YY. Requirements of transcription factor Smad-dependent and -independent TGF-beta signaling to control discrete T-cell functions. Proc Natl Acad Sci USA. (2012) 109:90510. doi: 10.1073/pnas.1108352109

50. Love PE, Bhandoola A. Signal integration and crosstalk during thymocyte migration and emigration. Nat Rev Immunol. (2011) 11:469-77. doi: 10.1038/nri2989

51. Lee PP, Fitzpatrick DR, Beard C, Jessup HK, Lehar S, Makar $\mathrm{KW}$, et al. A critical role for Dnmt1 and DNA methylation in $\mathrm{T}$ cell development, function, and survival. Immunity. (2001) 15:763-74. doi: 10.1016/S1074-7613(01)00227-8

52. Liu C, Saito F, Liu Z, Lei Y, Uehara S, Love P, et al. Coordination between CCR7- and CCR9-mediated chemokine signals in prevascular fetal thymus colonization. Blood. (2006) 108:2531-9. doi: 10.1182/blood-2006-05-024190

53. Jaffe AB, Hall A. Rho GTPases: biochemistry and biology. Annu Rev Cell Dev Biol. (2005) 21:247-69. doi: 10.1146/annurev.cellbio.21.020604.150721

54. Manresa-Arraut A, Johansen FF, Brakebusch C, Issazadeh-Navikas S, Hasseldam H. RhoA drives T-cell activation and encephalitogenic potential in an animal model of multiple sclerosis. Front Immunol. (2018) 9:1235. doi: 10.3389/fimmu.2018.01235

55. Lerner EC, Zhang TT, Knowles DB, Qian Y, Hamilton AD, Sebti SM. Inhibition of the prenylation of K-Ras, but not $\mathrm{H}$ - or N-Ras, is highly resistant to CAAX peptidomimetics and requires both a farnesyltransferase and a geranylgeranyltransferase I inhibitor in human tumor cell lines. Oncogene. (1997) 15:1283-8. doi: 10.1038/sj.onc. 1201296

56. Rosen SD. Ligands for L-selectin: homing, inflammation, and beyond. Annu Rev Immunol. (2004) 22:12956. doi: 10.1146/annurev.immunol.21.090501.080131

57. Brinkmann V, Billich A, Baumruker T, Heining P, Schmouder R, Francis G, et al. Fingolimod (FTY720): discovery and development of an oral drug to treat multiple sclerosis. Nat Rev Drug Discov. (2010) 9:88397. doi: $10.1038 / \mathrm{nrd} 3248$

Conflict of Interest: The authors declare that the research was conducted in the absence of any commercial or financial relationships that could be construed as a potential conflict of interest.

Copyright (C) 2021 Swan, Geng, Park, Ding, Zhou, Walcott, Zhang, Huang, Hammer and Wang. This is an open-access article distributed under the terms of the Creative Commons Attribution License (CC BY). The use, distribution or reproduction in other forums is permitted, provided the original author(s) and the copyright owner(s) are credited and that the original publication in this journal is cited, in accordance with accepted academic practice. No use, distribution or reproduction is permitted which does not comply with these terms. 